\title{
Reactive Compatibilization of Poly(Butylene Succinate)/Soy Protein Isolate Bio-Composites By Peroxide And Diacrylate Via Melt Blending
}

\section{Xiu-xian Zhou}

Nanjing Tech University

Qiang Dou ( $\nabla$ douqiang.njut@163.com )

Nanjing Tech University https://orcid.org/0000-0003-0539-2923

\section{Research Article}

Keywords: composite, polybutylene succinate, reactive compatibilization, soy protein isolate

Posted Date: August 3rd, 2021

DOl: https://doi.org/10.21203/rs.3.rs-734455/v1

License: (c) (1) This work is licensed under a Creative Commons Attribution 4.0 International License.

Read Full License 
Reactive compatibilization of poly(butylene succinate)/soy protein isolate bio-composites by peroxide and diacrylate via melt blending Xiu-xian Zhou, Qiang Dou*

College of Materials and Engineering, Nanjing Tech University, Nanjing 211816, PR China

* Corresponding author.

E-mail address: 1207753902@qq.com (X. Zhou), douqiang.njut@163.com (Q. Dou). 


\begin{abstract}
Poly(butylene succinate) (PBS)/soy protein isolate (SPI) bio-composites were reactive compatibilized by adding dibenzoyl peroxide (BPO) and hexanediol diacrylate (HDDA) via melt blending in an internal mixer. The structure and properties of composites were studied by scanning electron microscopy (SEM), Fourier transform infrared spectroscopy (FTIR), Soxhlet extraction experiments, dynamic mechanical analyses (DMA), rheological tests, contact angle measurements, thermogravimetric analyses (TGA), differential scanning calorimetry (DSC), wide-angle X-ray diffraction (WAXD), mechanical tests and water absorption tests. The results show that a branched graft copolymer (SPI-g-HDDA-g-PBS) was produced with the aid of BPO and HDDA via melt blending, which served as the compatibilizer and improved the compatibility and enhanced the adhesion between PBS matrix and SPI phase by forming a network structure in the composites. The crystal form of PBS was not changed in the composites. The melt viscocity and elasticity, hydrophobicity, thermal stability, crystallinity, tensile strength and water resistance of PBS/SPI-HDDA/BPO composites were improved compared with PBS/SPI composites.
\end{abstract}

Keywords: composite, polybutylene succinate, reactive compatibilization, soy protein isolate 


\section{Introduction}

Petroleum-based plastics have been extensively applied in various fields due to their excellent properties. With depleting petroleum resources and rising global concern for climate change, the development of biobased and biodegradable polymers has attracted much attention. [1,2] It is necessary to replace traditional petroleum-based commodity polymers such as polyolefins and poly(ethylene terephthalate) (PET) by biodegradable and biobased plastics, e.g., poly(lactic acid) (PLA), poly(butylene succinate) (PBS) and poly(hydroxy butyrate) (PHB). [3,4] Among biodegradable polymers, PBS is one of the most attractive polyester owing to outstanding mechanical properties, preferable heat and chemical resistance, melt-processability and biodegradability. [5] However, PBS shows the disadvantages of high cost and slow degradation rate, which limit its wide application. [6,7] Blending PBS with low-cost natural biodegradable polymers, e.g., starch [8] and protein [9], is a valid solution to this problem.

As a byproduct of soybean oil-extraction, soy protein (SP) has attracted considerable attention because of its renewability, biodegradability, abundance and low cost. [10] Soy flour (SF), soy protein concentrate (SPC) and soy protein isolate (SPI) are three grades of SP, containing ca. 50\%, $70 \%$ and $90 \%$ protein, respectively. [11] SP contains various amino acids, with glycinin (11S, ca. 52\%) and $\beta$-conglycinin (7S, ca. $35 \%)$ being the predominant ones. Both have quaternary structures with disulfide bonds binding polypeptide subunits together $[12,13]$. SP is characterized by numerous reactive groups, such as $-\mathrm{COOH},-\mathrm{OH}$ and $-\mathrm{NH}_{2}$, which could be used as 
sites for chemical modifications and polymerizations. [14,15] Indeed, cross-linking of SP could results in an increased molecular weight, and reduced elasticity and solubility. [16] Wet or dry (melt) processing are two methods to produce soy-based plastics, and the dry processing is preferable due to industrial friendly and easily adaptable. Plasticization and destructurization [17], graft copolymerization [18], oxidation [19], blending and compositing [20] are often used to modify the surface hydrophobicity, solubility, water-holding capacity, gelation and mechanical properties of SP-based plastics.

Over the past decades, a lot of research work has focused on biodegradable plastic/protein composites. Li et al. [21] improved the mechanical properties, water resistance, crystallization ability and biodegradation rate of $\mathrm{PBS} / \mathrm{SP}$ blends by introducing urethane and isocyanate groups. Ku-Marsilla and Verbeek [22] prepared Novatein thermoplastic protein (NTP)/PBS blends by using poly-2-ethyl-2-oxazoline (PEOX) and poly[(phenylisocyanate)-co-formaldehyde] (pMDI) as compatibilizers. Bonham et al. [23] compared the mixing methods of co-rotation (CR) and counter-rotation (CTR) twin-screw extrusions for a blend of plasticized SPI (PSPI) and PBS in a 30: 70 wt.-\% ratio. CTR extrusion provided enhanced interfacial adhesion, increased tensile elongation and prolonged thermal degradation temperatures because CTR allowed for better destruction and mixing of PSPI in the PBS matrix. Reddy et al. [24] studied the synergistic effect of simultaneous plasticization and denaturation of the reactive blending of thermoplastic SM (TSM) with polycaprolactone (PCL) and PBS, which had yielded biodegradable blends with 
improved tensile properties and elongation. Renoux et al. [25] successfully prepared plasticized isolated soy protein (PISP)/poly [(butylene succinate)-co-adipate] (PBSA) blends via single-step and two-step melt compounding methods, respectively. Compared with the two-step method, one-step method was an effective and timesaving method to enable thorough mixing and thus better dispersion of PISP into the PBSA. Chen and Zhang [26] processed SPC as a plastic by adjusting water content and blended it with poly(butylene adipate-co-terephthalate) (PBAT). Percolated thread structures were formed in SPC prior to compounding. Tensile properties were greatly improved in the blends with percolated SPC thread structures. Anstey et al. [27] investigated the processability and biodegradability of PBS/bio-based fillers (SM, canola meal (CM) and corn gluten meal (CGM)) composites using twin-screw compounding. The results showed that the biodegradation rate of PBS was increased due to the existence of meal-based fillers in the bio-composites, which enhanced the hydrolytic biodegradation of the material and facilitated micro-organism growth. Coltelli et al. [28] found that soy lecithin and the Schotten-Baumann modified whey were effective in compatibilizing the plasticized whey protein (PWP)/PBS blends. Significant increases in elastic modulus, tensile strength, elongation at break and crystallinity were observed with respect to the not compatibilized blend.

Soy protein shows strong hydrophilicity due to the polar groups, while PBS presents hydrophobicity due to the repeated aliphatic units. Generally, the poor interfacial adhesion between two incompatible polymers having different polarity will 
bring about inferior physical and mechanical properties. It is necessary to improve the compatibility of PBS and SPI by modification and compatibilization. [29,30] The reactive blending is a simple, effective and low-cost method to modulate interfacial interactions by in-situ chemical reaction, such as crosslinking and grafting, and thus enhances the properties of immiscible blends. [31] The reactive processing methods had been adopted in many studies, such as PBS/waxy starch [32], PBAT/thermoplastic starch [33], PWP/PBS [28], NTP/PBS [22], TSM/PCL/PBS [24] and SPC/Eastar Bio Copolyester (EPE) [34] composites.

Herein, the reactive blending method is adopted to compatibilize PBS/SPI composites by using dibenzoyl peroxide (BPO) as the initiator, hexanediol diacrylate (HDDA) as the grafting monomer. The compatibility, microstructures and properties of the composites were systematically investigated.

\section{Experimental}

\section{Materials}

Bio-PBS $^{\mathrm{TM}}$ (FZ91PB, produced from polymerization of bio-based succinic acid and 1,4-butanediol) was purchased from PTT MCC Biochem Co., Ltd. (Bangkok, Thailand). SPI (protein $\geq 90 \%$ (dry basis), fat $\leq 1 \%$, moisture $\leq 7 \%$, ash $\leq 6 \%$, crude fiber $\leq 1 \%$ and nitrogen soluble index (NSI) $\geq 85 \sim 95 \%$ ) was purchased from Shansong Biotechnology Co., Ltd. (Linyi, China). Dibenzoyl peroxide (BPO) was purchased from Sinopharm Chemical Reagent Co. Ltd. (Shanghai, China) and purified before use. Hexanediol diacrylate (HDDA) was obtained from Shanghai 
Yinchang New Material Co., Ltd. (Shanghai, China).

\section{Preparation Methods}

Firstly, PBS and SPI were vacuum dried at $80{ }^{\circ} \mathrm{C}$ for $8 \mathrm{~h}$ to remove the moisture before use. 100 grams of SPI and 2 grams of HDDA (2 wt $\%$ based on SPI) were thoroughly mixed in a blender at $20000 \mathrm{rpm}$ for 3 minutes, and the mixture was denoted as SPI-HDDA. Subsequently, an internal mixer (HL200, Jilin University Science and Technology Equipment Factory, Changchun, China) was used to prepare PBS/SPI composites (90/10, 80/20, 70/30, 60/40, 50/50 wt $\% / \mathrm{wt} \%)$ and PBS/SPI-HDDA/BPO composites (90/10/0.1, 80/20/0.1, 70/30/0.1, 60/40/0.1, $50 / 50 / 0.1 \mathrm{wt} \% / \mathrm{wt} \% / \mathrm{wt} \%$ ) at $130{ }^{\circ} \mathrm{C}$ and $45 \mathrm{rpm}$ for $8 \mathrm{~min}$. Then, a manual press (CH-0108, Changhong Equipment Co., Ltd., Dongguan, China) was used to compression mold test sheets $\left(100 \times 100 \times 1 \mathrm{~mm}^{3}\right)$ at $140{ }^{\circ} \mathrm{C}$ and $10 \mathrm{MPa}$ for $10 \mathrm{~min}$. Next, the sheets were cooled at room temperature and $10 \mathrm{MPa}$ for $10 \mathrm{~min}$ in another press. Finally, they were taken out from the mold and stored in a desiccator for further measurements.

\section{Tests Methods}

\section{Scanning electron microscopy (SEM) observations}

An SEM (JSM-6510, Tokyo, Japan) was used to observe the microstructures of PBS composites. The samples were frozen and fractured in liquid nitrogen. The newly fractured surfaces were coated with thin gold layers before SEM observations.

\section{Fourier transform infrared spectroscopy (FTIR) characterizations}

The functional groups in SPI, PBS and PBS composites before and after extractions 
were identified by an FTIR instrument (Vector 22, Bruker, Billerica, MA, USA). At room temperature, the spectra were scanned over the wavenumber range of 400 to $4000 \mathrm{~cm}^{-1}$, with 64 scans at a resolution of $4 \mathrm{~cm}^{-1}$. The ATR accessory was adopted on the surfaces of the samples.

\section{Crosslinked grafts contents determination}

In order to determine the content of crosslinked grafts in the composite, solvent extraction was used. To dissolve the PBS component, the sample (about $0.2 \mathrm{~g}$, cut into small pieces) was Soxhlet extracted with chloroform $(150 \mathrm{ml})$ at $70^{\circ} \mathrm{C}$ for 24 hours. The residue was considered as SPI-g-HDDA-g-PBS and SPI (SPI is insoluble in $\mathrm{CHCl}_{3}$ ), which was vacuum-dried to constant weight. The contents of crosslinked SPI-g-HDDA-g-PBS were calculated by Equation (1):

$$
\text { SPI-g-HDDA-g-PBS } \%=\frac{\mathrm{W}_{\mathrm{R}}-\mathrm{W}_{\mathrm{SPI}}}{\mathrm{W}_{0}} \times 100 \%
$$

where $\mathrm{W}_{\mathrm{R}}$ is the residue weight, $\mathrm{W}_{\text {SPI }}$ is the SPI weight in the raw sample and $\mathrm{W}_{0}$ is the raw sample weight, respectively. Three samples were used for each recipe and the average value was calculated.

\section{Dynamic mechanical analyses (DMA)}

A dynamic mechanical analyzer (Q800, TA Instruments, USA) was used to test PBS and PBS composites. The specimens $\left(25 \times 10 \times 1 \mathrm{~mm}^{3}\right)$ were tested using a tensile mode at a $1 \mathrm{~Hz}$ vibration frequency. The temperature range was -85 to $100{ }^{\circ} \mathrm{C}$ and the heating rate was $3{ }^{\circ} \mathrm{C} / \mathrm{min}$.

\section{Rheological tests}

The rheological tests were carried out in a rotational rheometer (MCR302, 
AntonPaar, Austria) with parallel plates (diameter $25 \mathrm{~mm}$ ). Frequency sweeping tests were performed from 0.1 to $100 \mathrm{~Hz}$ at $130^{\circ} \mathrm{C}$. To ensure lineal viscoelasticity and adequate signals in the solid and viscous states, strain amplitude was set at $1 \%$. The complex viscosity, storage and loss modulus were registered and expressed as functions of both time and temperature.

\section{Contact angle measurements}

The contact angles of water, diiodomethane on the surfaces of PBS and PBS composites were measured by a contact angle analyzer (YIKE-360B, Chengde, China). Before testing, absolute ethyl alcohol was used to clean the surfaces of the samples. The liquid (4 $\mu$ l) was dropped on the surfaces of the specimens with a micro syringe. The dynamic water contact angles $\left(\theta_{\text {water }}\right)$ were recorded every $20 \mathrm{~s}$ for $120 \mathrm{~s}$. Five replicates were tested for each sample to obtain the average value and the variance. The Owens and Wendt theory [30] was used to calculate surface free energies.

\section{Thermogravimetric analyses (TGA)}

The thermal stability of PBS, SPI and PBS composites were investigated by a TGA instrument (Netzsch STA 449C, Selb, Germany). The samples (10 15 mg) were heated from 40 to $800{ }^{\circ} \mathrm{C}$ with the heating rate of $10{ }^{\circ} \mathrm{C} / \mathrm{min}$ under the nitrogen flow. In addition, derivative thermogravimetry (DTG) curves were acquired to examine the weight loss rate as a function of temperature.

\section{Differential scanning calorimeter (DSC) measurements}

A DSC apparatus (ZF-DSC-D2, Shanghai Zufa Industry Co., Ltd., Shanghai, China) 
was used to evaluate the melting and crystallization behaviors of the specimens under nitrogen protection. Firstly, each specimen $(\sim 5 \mathrm{mg})$ was heated from room temperature to $150{ }^{\circ} \mathrm{C}$ at $10^{\circ} \mathrm{C} / \mathrm{min}$. It was maintained at $150{ }^{\circ} \mathrm{C}$ for 5 minutes to eliminate the thermal history. Subsequently, the samples were cooled to $30^{\circ} \mathrm{C}$ at $10{ }^{\circ} \mathrm{C} / \mathrm{min}$, and kept at $30{ }^{\circ} \mathrm{C}$ for 5 minutes. Finally, the samples were reheated to $150{ }^{\circ} \mathrm{C}$ at $10{ }^{\circ} \mathrm{C} / \mathrm{min}$.

Data was obtained from the first cooling and the second heating curves. The cooling curve provided the peak $\left(\mathrm{T}_{\mathrm{c}}^{\mathrm{p}}\right)$ and onset $\left(\mathrm{T}_{\mathrm{c}}^{\mathrm{on}}\right)$ crystallization temperatures. The melting temperature $\left(\mathrm{T}_{\mathrm{m}}\right)$ was determined by the second melting curve. The crystallinity $\left(\mathrm{X}_{\mathrm{c}}\right)$ of the specimens was calculated by the following Formula (2):

$$
\mathrm{X}_{\mathrm{c}}=\frac{\Delta \mathrm{H}_{\mathrm{m}}}{\Delta \mathrm{H}_{\mathrm{m}}^{0} \omega_{\mathrm{PBS}}}
$$

where $\omega_{\mathrm{PBS}}$ is the PBS wt $\%$ in the composite, $\Delta \mathrm{H}_{\mathrm{m}}^{0}$ represents the enthalpy of $100 \%$ crystalline PBS and $\Delta \mathrm{H}_{\mathrm{m}}^{0}=200 \mathrm{~J} / \mathrm{g}$. [35]

\section{Wide angle X-ray diffraction (WAXD) analyses}

An X-ray diffractometer (SmartLab, Rigaku, Tokyo, Japan) was used to characterize the crystal structures of SPI, PBS and PBS composites at room temperature, operating with $\mathrm{Cu} \mathrm{K}_{\alpha}(1.5418 \AA)$, from $5^{\circ}$ to $55^{\circ}$ at a scan speed of $10 \%$ min.

The Scherrer's equation (3) was used to calculate the grain size of PBS in the composites.

$$
\mathrm{D}_{\mathrm{hkl}}=\frac{\mathrm{k} \lambda}{\beta \cos \theta}
$$

where $D_{\mathrm{hkl}}(\mathrm{nm})$ represents the crystallite size (hkl) perpendicular to the crystal plane; 
$\mathrm{k}$ symbols the crystal shape factor and $\mathrm{k}=0.89 ; \lambda$ is the $\mathrm{X}$-ray wavelength $(\mathrm{nm}) ; \theta$ is the diffraction angle; $\beta$ represents the peak width at half-height.

\section{Mechanical tests}

Tensile tests were carried out by using a universal testing machine (MZ-4000D1, Jiangsu Mingzhu Test Machine Co., Ltd, Jiangdu, China) according to ISO 527-2012. The test sheets were cut into the specimens (ISO 527-1BA) and stored in a desiccator at $23{ }^{\circ} \mathrm{C}$ for 24 hours. The crosshead speed was set at $10 \mathrm{~mm} / \mathrm{min}$. Five replicates were tested for each recipe to obtain the average value and the variance.

\section{Water absorption (WA) tests}

The samples were dried in a vacuum oven at $50^{\circ} \mathrm{C}$ until constant weights $\left(\mathrm{m}_{1}\right)$ were obtained. Subsequently, the samples were immersed in the distilled water at room temperature, and they were taken out at specific time intervals. Tissue papers were used to gently absorb the excess water on the surfaces of the samples and then they were weighed as $m_{2}$. WA values were calculated by Equation (4):

$$
\mathrm{WA} \%=\frac{\mathrm{m}_{2}-\mathrm{m}_{1}}{\mathrm{~m}_{1}} \times 100 \%
$$

\section{Results and Discussion}

\section{SEM observations}



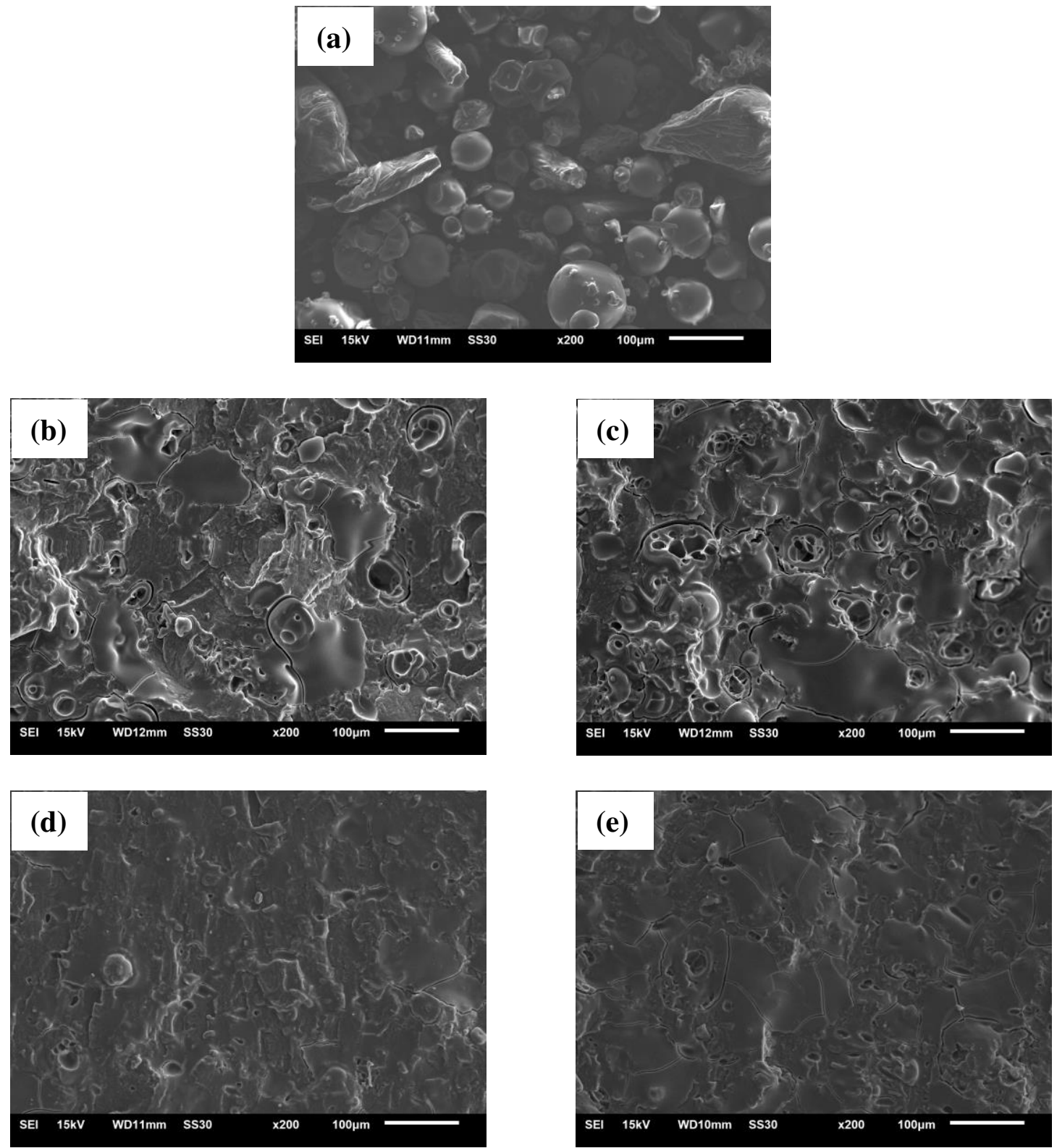

Fig.1 SEM micrographs of SPI and the cryogenically fractured surfaces of PBS composites.

(a) SPI, (b) PBS/SPI (80/20) composite, (c) PBS/SPI (60/40) composite, (d)

PBS/SPI-HDDA/BPO (80/20/0.1) composite, (e) PBS/SPI-HDDA/BPO (60/40/0.1) composite

It is well known that the physical, chemical, mechanical, rheological and processing properties of polymer blends are dependent on their phase morphologies, especially for mechanical properties. [36] Figure 1 presents the phase morphologies of SPI and the cryogenically fractured surfaces of the composites. As shown in Fig. 1(a), 
the appearance of most SPI particles is elliptical or spherical, and their sizes are between 10 and $100 \mu \mathrm{m}$, except for a few irregular particles are beyond $100 \mu \mathrm{m}$.

Figures 1(b) and 1(c) show the cryogenically fractured surfaces of PBS/SPI composites. The fractured surfaces are coarse, accompanying with large holes and interstices, suggesting poor consolidation between two-phase's interfaces. Soy protein shows strong hydrophilicity due to the polar groups, while PBS shows hydrophobicity due to the repeated aliphatic units. This disparity results in poor interfacial adhesion between two phases. Therefore, it is difficult to achieve desired properties in case of PBS/SPI blends due to the existence of high interfacial tension between two phases.[22]

Figures 1(d) and 1(e) show the cryogenically fractured surfaces of PBS/SPI-HDDA/BPO composites. Compared with PBS/SPI composites, the fractured surfaces of PBS/SPI-HDDA/BPO composites become smoother, fewer holes and interstices are observed. Zhu et al. [11] reported that the compatibility between SPC and PLA was improved by addition of a compatibilizer (PLA-g-maleic anhydride (MA)). Therefore, the adhesion between SPI and PBS is greatly enhanced by adding BPO and HDDA, attributing to the generation of the crosslinked grafts between two phases, serving as the compatibilizer.

\section{FTIR analyses}




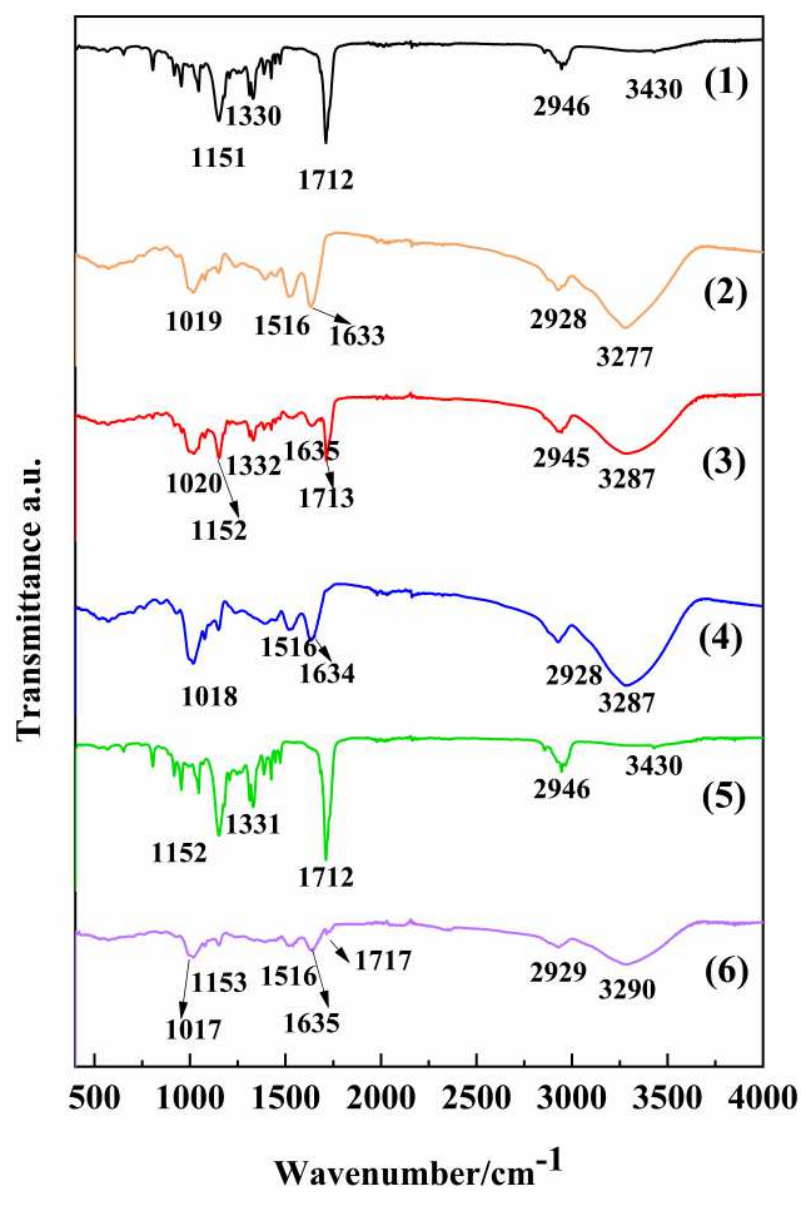

Fig. 2 FTIR spectra of PBS, SPI and PBS composites before and after extraction.

(1) PBS, (2) SPI, (3) PBS/SPI (60/40) composite, (4) residue of PBS/SPI (60/40) composite after extraction, (5) PBS/SPI-HDDA/BPO (60/40/0.1) composite, (6) residue of PBS/SPI-HDDA/BPO (60/40/0.1) composite after extraction.

Table 1 The SPI-g-HDDA-PBS content after extraction by chloroform

\begin{tabular}{cc}
\hline Sample & SPI-g-HDDA-g-PBS/wt $\%$ \\
\hline PBS/SPI (80/20) & 1.51 \\
PBS/SPI (60/40) & 1.76 \\
PBS/SPI-HDDA/BPO (80/20/0.1) & 16.07 \\
PBS/SPI-HDDA/BPO (60/40/0.1) & 19.75 \\
\hline
\end{tabular}

The FTIR is an effective tool to investigate the reactions and interactions between 
functional groups of the composites. Figure 2 shows FTIR spectra of PBS, SPI and PBS composites before and after extraction. On Curve (1) of the pure PBS, five representative absorption bands at $3430 \mathrm{~cm}^{-1}$ (O-H stretching), $2946 \mathrm{~cm}^{-1}\left(-\mathrm{CH}_{2}\right.$ asymmetric stretching), $1712 \mathrm{~cm}^{-1}$ (-C=O stretching), $1330 \mathrm{~cm}^{-1}(-\mathrm{CH}-$ symmetric stretching) and $1151 \mathrm{~cm}^{-1}$ (-C-O-C- stretching) are observed. [37] On Curve (2) of SPI, SPI exhibits strong absorption bands at $3277 \mathrm{~cm}^{-1}$ (O-H and N-H stretching), 2928 $\mathrm{cm}^{-1}$ (- $\mathrm{CH}_{2}$ stretching), $1633 \mathrm{~cm}^{-1}\left(\mathrm{C}=\mathrm{O}\right.$ stretching (amide I band)), $1516 \mathrm{~cm}^{-1}(\mathrm{~N}-\mathrm{H}$ bending (amide II band)) and $1019 \mathrm{~cm}^{-1}$ (C-O stretching), respectively. [38] The Curve (3) (PBS/SPI (60/40) composite before extraction) shows both characteristic peaks of PBS $\left(2945,1713,1332\right.$ and $\left.1152 \mathrm{~cm}^{-1}\right)$ and SPI $\left(3287,1635\right.$ and $\left.1020 \mathrm{~cm}^{-1}\right)$. The red shift of O-H and N-H stretching band from $3277 \mathrm{~cm}^{-1}$ (Curve 2) to $3287 \mathrm{~cm}^{-1}$ (Curve 3) is attributed to the loss of the bound water in SPI during melt processing. However, the characteristic peaks of PBS disappear on the Curve (4) (PBS/SPI (60/40) composite after chloroform extraction), the peaks of SPI $(3287,2928,1634,1516$, and $1018 \mathrm{~cm}^{-1}$ ) retain. It reflects that there is no special interaction between PBS and SPI because the PBS matrix is extracted out by chloroform.

The Curve (5) (PBS/SPI-HDDA/BPO (60/40/0.1) composite before extraction) has similarity to that of the pure PBS, showing PBS peaks at 3430, 2946, 1712, 1331 and $1152 \mathrm{~cm}^{-1}$, indicating that PBS molecules are predominant on the surface of PBS/SPI-HDDA/BPO (60/40/0.1) composite. Obviously, the existence of the crosslinked graft copolymer enhances the adhesion between PBS and SPI phases, resulting in PBS molecules encapsulate the SPI particles. Therefore, the characteristic 
peaks related to PBS are observed. The Curve (6) (PBS/SPI-HDDA/BPO (60/40/0.1) composite after extraction) presents both characteristic peaks of PBS (1717 and 1153 $\mathrm{cm}^{-1}$ ) and SPI $\left(3290,2929,1635,1516\right.$ and $\left.1017 \mathrm{~cm}^{-1}\right)$. It indicates that the crosslinked graft copolymer, i.e., SPI-g-HDDA-g-PBS is formed between PBS and SPI phases during the melt blending.

Table 1 shows the crosslinked graft copolymer (SPI-g-HDDA-g-PBS) contents in the composites after chloroform extraction. The graft contents of PBS/SPI composites are very low. On the other hand, the SPI-g-HDDA-g-PBS contents of PBS/SPI-HDDA/BPO composites increase significantly, proving that the crosslinked graft copolymer is produced between PBS and SPI with the addition of HDDA and BPO during the melt blending.

The proposed reactive formation mechanism of SPI-g-HDDA-g-PBS is shown in Fig. 3. Firstly, BPO decomposes to form peroxy radicals $(\mathrm{RO} \bullet)$ under heating and shearing in the mixer. Secondly, the hydrogen atoms on the chains of PBS and SPI are detached by RO• to form the macroradicals of PBS and SPI, respectively. Finally, the double bonds at both ends of HDDA are opened to connect with the macroradicals of PBS and SPI, and thus the crosslinked graft copolymer is formed. The proposed reactive formation mechanism in Fig. 3 is a simple example, and the actual situation is more complicated, for example, it is possible to produce a branched entangled network connected with multiple PBS and SPI macromolecules. 


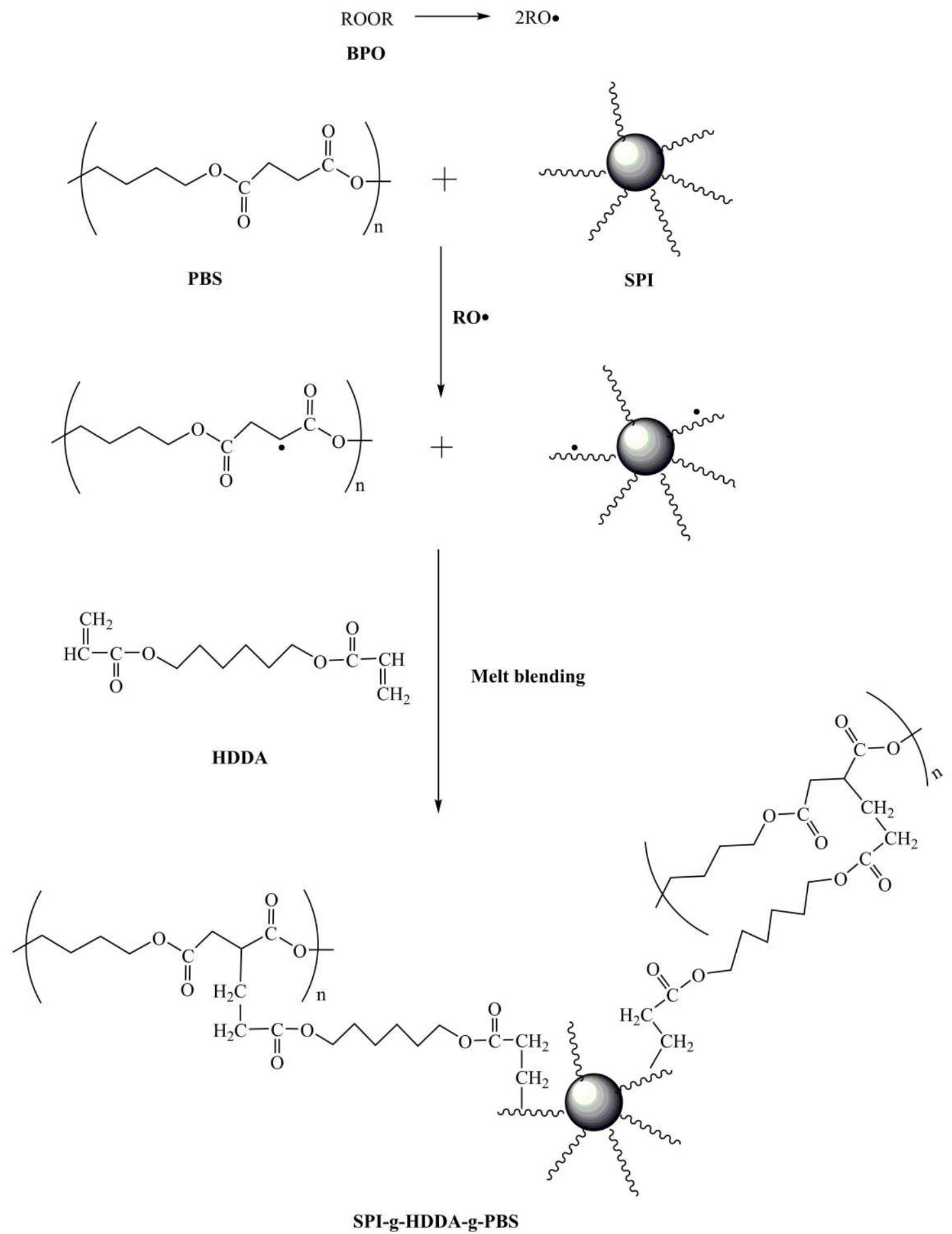

Fig. 3 The proposed reactive formation mechanism of SPI-g-HDDA-g-PBS

\section{DMA characterizations}



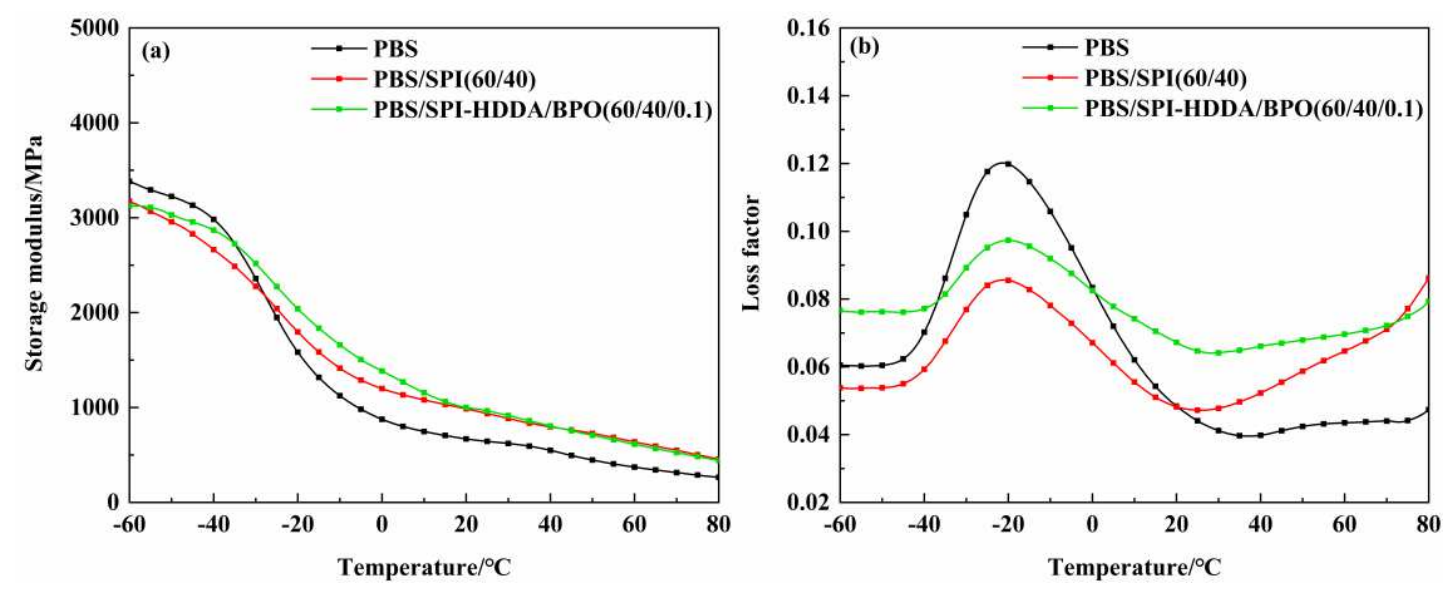

Fig. 4 DMA curves of PBS and PBS composites.

(a) storage modulus, (b) loss factor.

Table 2 DMA data of PBS and PBS composites.

\begin{tabular}{ccc}
\hline Sample & $\mathrm{T}_{\mathrm{g}}\left({ }^{\circ} \mathrm{C}\right)$ & $\mathrm{E}^{\prime}$ at $23^{\circ} \mathrm{C}(\mathrm{MPa})$ \\
\hline PBS & -21.19 & 650.82 \\
PBS/SPI (60/40) & -20.77 & 945.10 \\
PBS/SPI-HDDA/BPO (60/40/0.1) & -21.06 & 981.89 \\
\hline
\end{tabular}

The effect of BPO and HDDA on the mechanical and compatibility of PBS/SPI composites is evaluated by the DMA. The storage modulus (E') and loss factor ( $\tan \delta$ ) of the composites as a function of temperature are shown in Fig. 4, and Table 2 lists the DMA parameters. Figure 4(a) shows that the E' values of all specimens decrease with increasing temperature, indicating to the softening of the PBS matrix. Moreover, the sharp decrease between -40 and $-20{ }^{\circ} \mathrm{C}$ corresponds to the glass transition region of the PBS matrix. [39] In addition, the E' values of PBS composites are larger than that of the pure PBS above $-27^{\circ} \mathrm{C}$, indicating that the SPI filler hinders the movement of the PBS chains, resulting in larger E' values at $23{ }^{\circ} \mathrm{C}$ of the composites (Table 2). Moreover, the E' value of PBS/SPI-HDDA-BPO (60/40/0.1) composite is larger than 
that of PBS/SPI (60/40) composite between -60 and $40{ }^{\circ} \mathrm{C}$. In PBS/SPI-HDDA/BPO (60/40/0.1) composite, the presence of some graft copolymers leads to macromolecular crosslinks and entanglements. Therefore, the E' of PBS/SPI-HDDA/BPO (60/40/0.1) composite is larger than that of PBS/SPI (60/40) composite between -60 and $40{ }^{\circ} \mathrm{C}$. However, the crosslinked SPI-g-HDDA-g-PBS content is limited (Table 1), and thus the mobility of macromolecular chains is increased as the temperature rises, leading to the similar E' values of PBS composites above $40{ }^{\circ} \mathrm{C}$.

The compatibility between polymers is reflected by the variation of glass transition temperature $\left(\mathrm{T}_{\mathrm{g}}\right)$. All samples show single relaxation peak between -40 and $20{ }^{\circ} \mathrm{C}$, corresponding to the $\mathrm{T}_{\mathrm{g}}$ of PBS. It can be seen from Table 2 that the $\mathrm{T}_{\mathrm{g}}$ of the pure PBS is $-21.19{ }^{\circ} \mathrm{C}$. For PBS/SPI (60/40) composite, the $\mathrm{T}_{\mathrm{g}}$ increases to $-20.77{ }^{\circ} \mathrm{C}$, indicating that the addition of SPI limits the movement of the macromolecular chains. However, the $\mathrm{T}_{\mathrm{g}}$ of PBS/SPI-HDDA/BPO (60/40/0.1) composite slightly reduces to $-21.06{ }^{\circ} \mathrm{C}$, attributing to the existence of SPI-g-HDDA-g-PBS improves the compatibility between two phases. [32,40] Furthermore, the height of $\tan \delta$ peak may be an indicator for the microstructure of the polymer composite. Compared with the high loss peak of the pure PBS, the peak height of PBS/SPI (60/40) and PBS/SPI-HDDA/BPO (60/40/0.1) composites decreases gradually because the addition of SPI disturbs the PBS molecular mobility. Moreover, the presence of SPI-g-HDDA-g-PBS enhances the interactions between PBS and SPI, leading to a further decrease in the peak height of $\tan \delta$. 


\section{Rheological tests}
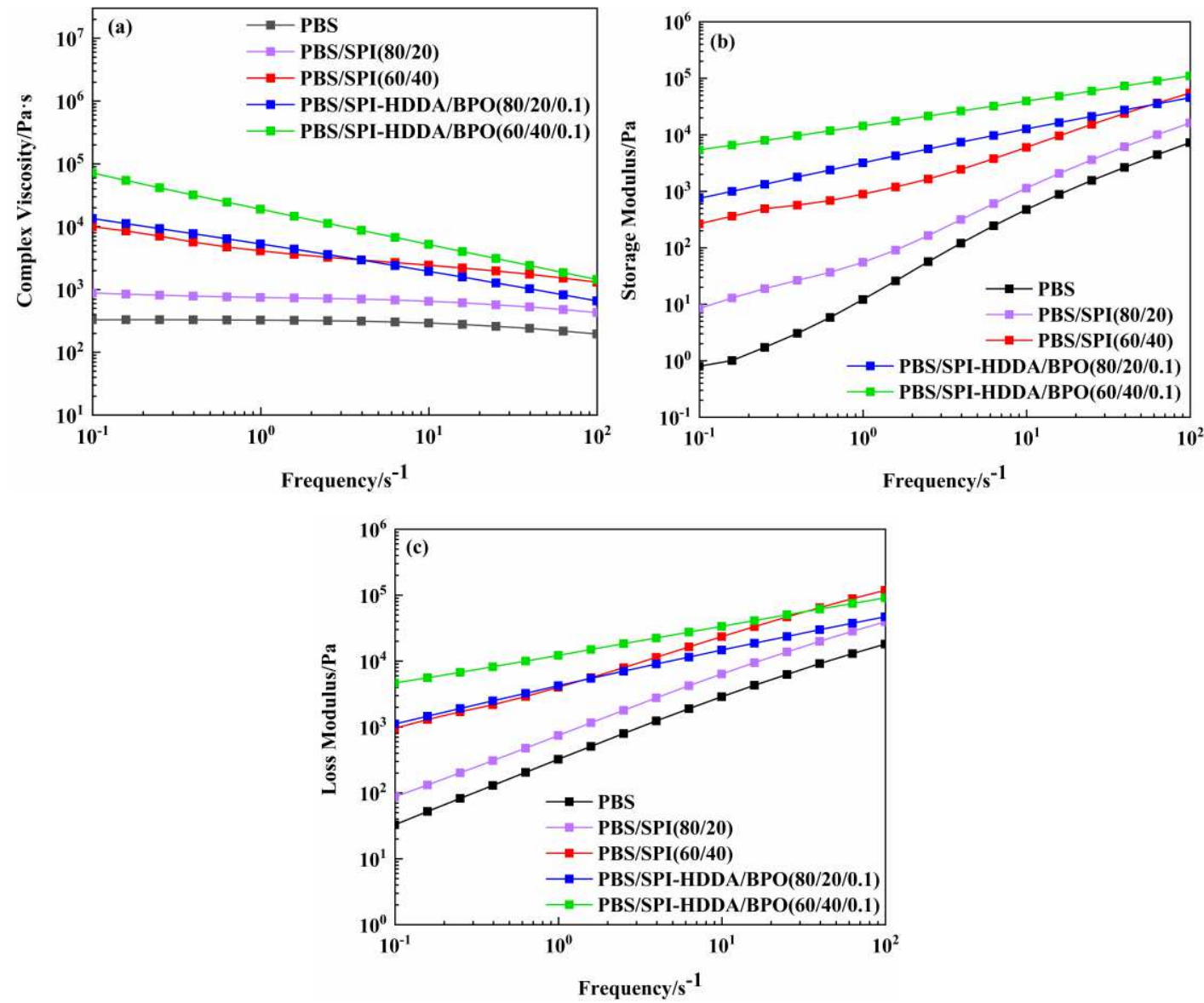

Fig. 5 Rotational rheological properties of PBS and PBS composites.

(a) complex viscosity, (b) storage modulus, (c) loss modulus

Rheological properties in the molten state are essential to evaluate the processability of polymer composites, while dynamic rheological properties reflect the microstructure and interactions of the polymer melt. Figure 5 shows the rotational rheological properties of PBS and PBS composites. As shown in Fig. 5(a) the dynamic complex viscosity $\left(\eta^{*}\right)$ curve of the pure PBS maintains almost constant at low frequencies and decreases a little at high frequencies, indicating that the chain scission phenomenon leads to a slight decrease of molecular weight. [41] Meanwhile, the $\eta^{*}$ curves of PBS composites show non-Newtonian behaviors throughout the 
entire frequency range, which has shear thinning characteristics. The $\eta^{*}$ values of PBS composites increase with the increasing SPI content throughout the range, indicating that the addition of SPI particles impedes the movement of PBS chains. Furthermore, the $\eta^{*}$ values of PBS/SPI-HDDA/BPO composites are larger than those of PBS/SPI composites, especially at low frequencies. Because the presence of entangled network structures changes the rheological properties, displaying increased viscosity. [42] The existence of crosslinked branches also leads to the linearization enhancements of the curves, reflecting the enhanced Newtonian behavior of the melt.

Figure 5(b) show the storage modulus (G') of PBS and PBS composites, which characterize the elasticity of the polymer melt. [43] It is obvious that $G^{\prime}$ increases with the increasing frequency, reflecting an increase of elasticity. The material stores more energy at high frequencies due to the insufficient time for polymeric molecular segments to relax. The G' value increases with the SPI content, indicating that polymer chains are partly adsorbed on the filler surfaces and partly entangled with the adjacent ones. [44] Oliviero et al. [45] also found that the melt elasticity of thermoplastic gelatin (TPG)/PBS composites increased with the TPG content. Furthermore, the G' values of PBS/SPI-HDDA/BPO composites are larger than those of PBS/SPI composites, indicating that the presence of SPI-g-HDDA-g-PBS enhances the interaction and entanglement between two phases by forming a network structure in the blends. Therefore, PBS/SPI-HDDA/BPO composites would absorb more energy and have greater elasticity than PBS/SPI composites. Su et al. [46] also discovered that the G' of carboxymethyl chitosan (CMCS)-graft-PLA increased with 
the increase of crosslinking density, it is thought that the blend became more elastic with the addition of the compatibilizer which was formed at the interface.

Figure 5(c) shows the loss modulus (G") curves of the composites, which show the similar trends to the $G^{\prime}$ curves. However, it can be seen that the changes of $G^{\prime}$ is more obvious than G" for each specimen, indicating that the composite structure is more responsive to $G^{\prime}$ than $G$ '. [32]

\section{Contact angle characterizations}

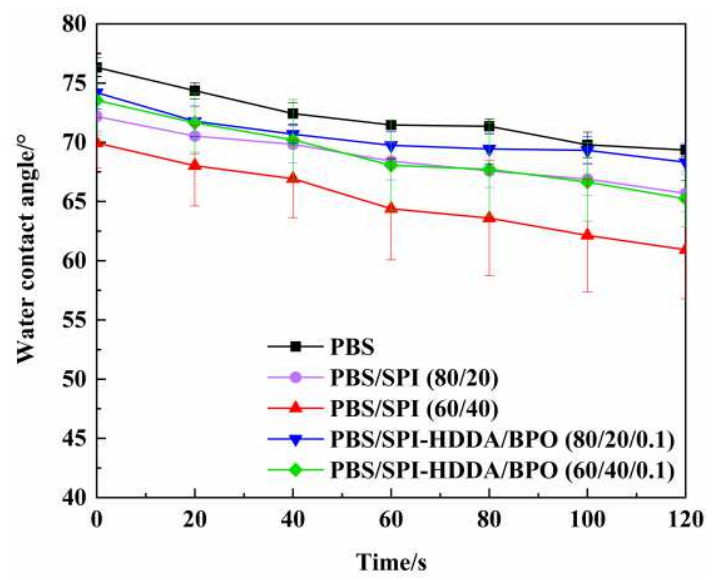

Fig. 6 Water contact angle curves of PBS and PBS composites.

Generally, the water contact angle $\left(\theta_{\text {water }}\right)$ characterizes the hydrophilic/hydrophobic properties of the material's surface. Figure 6 shows the $\theta_{\text {water }}$ curves of PBS and PBS composites. The $\theta_{\text {water }}$ of the pure PBS is higher than those of PBS composites, indicating the hydrophobicity of PBS. In addition, the presence of SPI in the blends results in a decrease of the $\theta_{\text {water }}$ with the time, especially for the composites with higher SPI contents, because the hydrophilic SPI is rich in polar groups (e.g., $-\mathrm{OH},-\mathrm{COOH}$ and $-\mathrm{NH}_{2}$ ). [47] Moreover, the $\theta_{\text {water }}$ values of PBS/SPI-HDDA/BPO composites are higher than those of PBS/SPI composites. Because the existence of SPI-g-HDDA-g-PBS enhances the interaction between PBS 
and SPI and facilitates to encapsulate SPI particles by PBS molecules, resulting in PBS-rich surfaces, as shown in Fig. 2 (Curve (5)). Therefore, the hydrophobicity of PBS/SPI-HDDA/BPO composites is increased.

In order to further study the polarity and interactions within the composites, the Owens and Wendt's method is selected, and the dispersive $\left(\gamma_{\mathrm{s}}^{\mathrm{d}}\right)$ and polar $\left(\gamma_{\mathrm{s}}^{\mathrm{p}}\right)$ components of the surface energy $\left(\gamma_{\mathrm{s}}\right)$ can be calculated according to Equations (5-7).

$$
\begin{gathered}
\sqrt{\gamma_{\mathrm{s}}^{\mathrm{d}}}=\frac{\left(1+\cos \theta_{2}\right) \gamma_{\mathrm{L} 2} \sqrt{\gamma_{\mathrm{L} 1}^{\mathrm{p}}}-\left(1+\cos \theta_{1}\right) \gamma_{\mathrm{L} 1} \sqrt{\gamma_{\mathrm{L} 2}^{\mathrm{p}}}}{2 \sqrt{\gamma_{\mathrm{L} 2}^{\mathrm{d}} \gamma_{\mathrm{L} 1}^{\mathrm{p}}}-2 \sqrt{\gamma_{\mathrm{L} 1}^{\mathrm{d}} \gamma_{\mathrm{L} 2}^{\mathrm{p}}}} \\
\sqrt{\gamma_{\mathrm{S}}^{\mathrm{p}}}=\frac{\left(1+\cos \theta_{2}\right) \gamma_{\mathrm{L} 2} \sqrt{\gamma_{\mathrm{L} 1}^{\mathrm{d}}}-\left(1+\cos \theta_{1}\right) \gamma_{\mathrm{L} 1} \sqrt{\gamma_{\mathrm{L} 2}^{\mathrm{d}}}}{2 \sqrt{\gamma_{\mathrm{L} 2}^{\mathrm{p}} \gamma_{\mathrm{L} 1}^{\mathrm{d}}}-2 \sqrt{\gamma_{\mathrm{L} 1}^{\mathrm{p}} \gamma_{\mathrm{L} 2}^{\mathrm{d}}}} \\
\gamma_{\mathrm{S}}=\gamma_{\mathrm{S}}^{\mathrm{d}}+\gamma_{\mathrm{S}}^{\mathrm{p}}
\end{gathered}
$$

where $\gamma_{\mathrm{s}}$ is the surface free energy $(\mathrm{N} / \mathrm{m}), \theta_{1}$ and $\theta_{2}$ represent the initial $\theta$ values of probe liquids $\left(^{\circ}\right), \gamma_{\mathrm{L} 1}^{\mathrm{d}}, \gamma_{\mathrm{L} 1}^{\mathrm{p}}, \gamma_{\mathrm{L} 2}^{\mathrm{d}}$ and $\gamma_{\mathrm{L} 2}^{\mathrm{p}}$ are the dispersion, and polarity components of the probe liquids, respectively.

Table 3 The components of surface energies of the test liquids

\begin{tabular}{cccc}
\hline Test liquid & $\gamma\left(\mathrm{mJ} / \mathrm{m}^{2}\right)$ & $\gamma^{\mathrm{d}}\left(\mathrm{mJ} / \mathrm{m}^{2}\right)$ & $\gamma^{\mathrm{p}}\left(\mathrm{mJ} / \mathrm{m}^{2}\right)$ \\
\hline Water & 72.8 & 26.0 & 46.8 \\
Diiodomethane & 50.8 & 48.5 & 2.3 \\
\hline
\end{tabular}

Table 4 Interfacial characteristics of PBS and PBS composites

\begin{tabular}{cccccc}
\hline Sample & $\theta_{\text {water }}\left(^{\circ}\right)$ & $\theta_{\mathrm{CH} 2 \mathrm{I} 2}\left(^{\circ}\right)$ & $\gamma_{\mathrm{s}}^{\mathrm{d}}\left(\mathrm{mJ} / \mathrm{m}^{2}\right)$ & $\gamma_{\mathrm{s}}^{\mathrm{p}}\left(\mathrm{mJ} / \mathrm{m}^{2}\right)$ & $\gamma_{\mathrm{s}}\left(\mathrm{mJ} / \mathrm{m}^{2}\right.$ \\
& & & & \\
\hline PBS & 76.32 & 36.17 & 37.92 & 3.97 & 41.89 \\
\hline
\end{tabular}




\begin{tabular}{cccccc}
\hline PBS/SPI (80/20) & 72.18 & 42.11 & 33.38 & 7.00 & 40.38 \\
PBS/SPI (60/40) & 69.95 & 45.21 & 30.96 & 9.00 & 39.97 \\
PBS/SPI-HDDA/BPO & & & & & \\
(80/20/0.1) & 74.19 & 39.51 & 35.44 & 5.46 & 40.90 \\
PBS/SPI-HDDA/BPO & & & & & \\
$(60 / 40 / 0.1)$ & 73.54 & 41.56 & 34.04 & 6.20 & 40.25 \\
\hline
\end{tabular}

Table 3 presents the components of surface energies of the detect liquids. Water $\left(\mathrm{H}_{2} \mathrm{O}\right)$ and diiodomethane $\left(\mathrm{CH}_{2} \mathrm{I}_{2}\right)$ are selected as experimental liquids due to the different polarities of them. Table 4 presents the initial $\theta$ values and surface energies of PBS and PBS composites. Compared with the pure PBS, the $\gamma_{\mathrm{s}}^{\mathrm{d}}$ of PBS composites decreases with the SPI content, while the $\gamma_{\mathrm{s}}^{\mathrm{p}}$ increases. Because SPI brings in active polar groups such as, $-\mathrm{COOH},-\mathrm{OH}$ and $-\mathrm{NH}_{2}$, resulting in the increasing polarity of the composite. The $\gamma_{\mathrm{s}}^{\mathrm{p}}$ values of PBS/SPI-HDDA/BPO composites are lower than those of PBS/SPI composites, indicating that hydrophobic PBS molecules are dominant on the surfaces due to the appearence of the branched graft copolymer in PBS/SPI-HDDA/BPO composites.

\section{TG analyses}



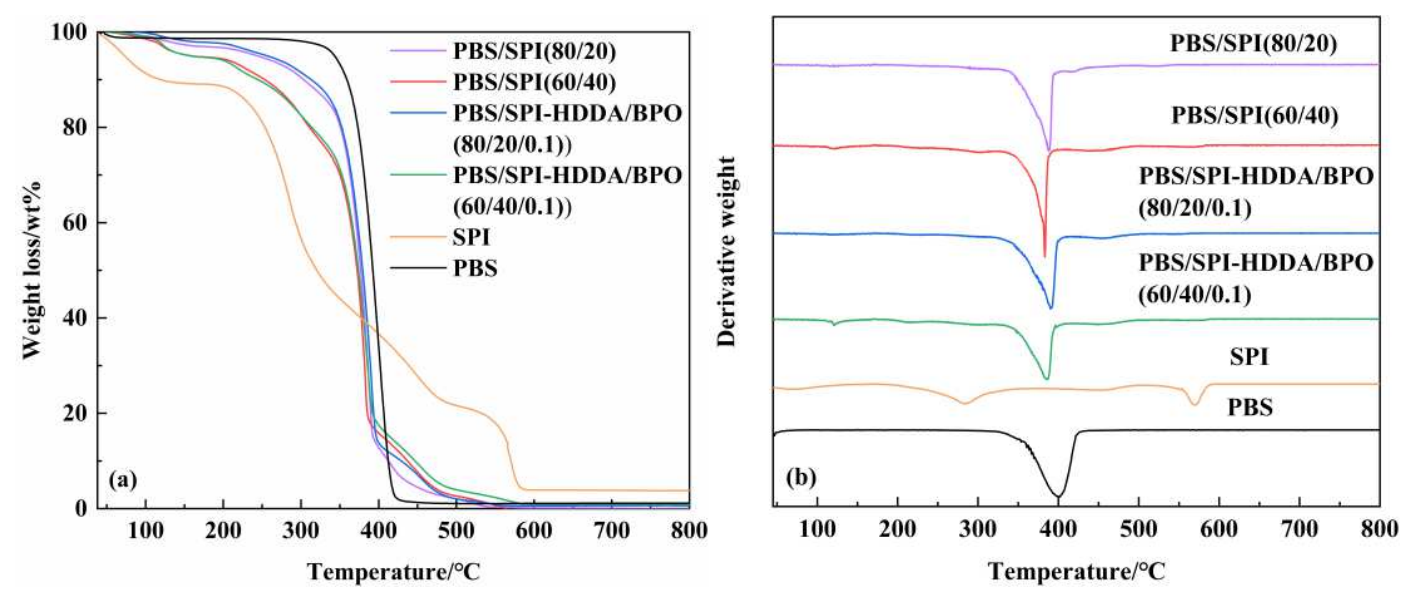

Fig. 7 TG and DTG curves of SPI, PBS and PBS composites.

(a) TGA curves, (b) DTG curves.

Table 5 TGA data of SPI, PBS and PBS composites

\begin{tabular}{ccccc}
\hline & $\mathrm{T}_{5 \%}$ & $\mathrm{~T}_{\max , \mathrm{SPI}}$ & $\mathrm{T}_{\max , \text { PBS }}$ & $\mathrm{E}_{\mathrm{t}, \text { PBS }}$ \\
& $\left({ }^{\circ} \mathrm{C}\right)$ & $\left({ }^{\circ} \mathrm{C}\right)$ & $\left({ }^{\circ} \mathrm{C}\right)$ & $(\mathrm{KJ} / \mathrm{mol})$ \\
\hline SPI & 73.10 & $\begin{array}{c}282.55 / \\
570.71\end{array}$ & - & - \\
PBS & 342.62 & - & 399.43 & 225.27 \\
PBS/SPI (80/20) & 243.61 & - & 387.21 & 150.04 \\
PBS/SPI (60/40) & 159.13 & 121.77 & 384.29 & 105.95 \\
PBS/SPI-HDDA/BPO (80/20/0.1) & 256.62 & - & 390.99 & 151.86 \\
& & & & \\
PBS/SPI-HDDA/BPO (60/40/0.1) & 157.17 & 120.74 & 385.32 & 106.28 \\
\hline
\end{tabular}

The TGA is very useful for quantitatively determining the degradation behavior and composition of composites, and it also exhibits the interaction between the components. Figure 7 furnishes TG curves and derivative thermogravimetric (DTG) curves of SPI, PBS and PBS composites. Table 5 provides the initial degradation temperature ( $\mathrm{T}_{5} \%$, the temperature at the $5 \%$ weight loss), the temperature at maximum degradation rate $\left(\mathrm{T}_{\mathrm{d}, \max }\right)$ and the activation energy for thermal 
decomposition $\left(\mathrm{E}_{\mathrm{t}}\right)$ of SPI, PBS and PBS composites.

The TGA data are used to calculate the $\mathrm{E}_{\mathrm{t}}$ of the composites with Equation (8).

$$
\ln \left[\ln (1-\alpha)^{-1}\right]=\frac{E_{t} \theta}{\mathrm{RT}_{\max }^{2}}
$$

where $\theta$ is $\left(\mathrm{T}-\mathrm{T}_{\max }\right), \mathrm{T}$ is the temperature, $\alpha$ is the decomposed fraction, $\mathrm{R}$ is the gas constant. $E_{t}$ can be calculated from the slope of $\ln \left[\ln (1-\alpha)^{-1}\right]$ vs $\theta$. [48]

As shown in Fig. 7, the TG curve of the pure PBS has one step, corresponding to the single peak on DTG curve. In addition, the thermal degradation of SPI can be divided into four stages. The first transition is the evaporation of the residual moisture in SPI before $120{ }^{\circ} \mathrm{C}$. The second step from 180 to $330{ }^{\circ} \mathrm{C}$ due to the degradation of small molecules and the breakdown of some unstable chemical bonds in SPI. The third stage is the degradation of the backbone peptides between 330 and $480{ }^{\circ} \mathrm{C}$. The last stage above $520{ }^{\circ} \mathrm{C}$ represents the carbonization and charring of SPI phase. Two obvious peaks located at 282.55 and $570.71{ }^{\circ} \mathrm{C}$ can be seen on the DTG curve of SPI. [49]

The TG curves of the composites exist between those of SPI and PBS. With the increase of SPI content, they approach to SPI curve. However, there is single obvious degradation peak on the DTG curves of PBS composites, corresponding to the PBS phase in the blends. Two DTG peaks of SPI phase cannot be observed for the composites. Only when SPI content is $40 \%$, a small peak of the loss of moisture appears on the DTG curves of the blends.

As shown in Table 5, the T5\% of SPI $\left(73.10{ }^{\circ} \mathrm{C}\right)$ is lower than that of the pure PBS $\left(342.62{ }^{\circ} \mathrm{C}\right)$. The $\mathrm{T}_{5} \%$ of PBS composites is lower than that of the pure PBS, and it 
decreases with SPI content, indicating that SPI decreases the initial thermal stability of the blends. Moreover, with the addition of SPI, the $\mathrm{T}_{\max }$, PBS values of the composites are lower than that of the pure PBS, due to poor thermal stability of SPI. Furthermore, the $\mathrm{T}_{\max }$ PBS values of PBS/SPI-HDDA/BPO composites are larger than those of PBS/SPI composites, indicating that the presence of SPI-g-HDDA-g-PBS enhances the adhesion between PBS and SPI, leading to improved thermal stability.

It is meaningful to study the thermal degradation kinetics and degradation mechanisms of materials by calculating the $E_{t}$. [50] The $E_{t}$ of the pure PBS is the largest, meaning that the pure PBS is thermally stable than others. The addition of SPI decreases the $E_{t}$ of the composites, due to its poor thermal stability. In addition, the presence of SPI-g-HDDA-g-PBS in PBS/SPI-HDDA/BPO composites may improve the thermal stability, contributing to higher $\mathrm{E}_{\mathrm{t}}$ than that of PBS/SPI composites. These results are consistent with $\mathrm{T}_{\max }$ PBS values.

\section{DSC measurements}
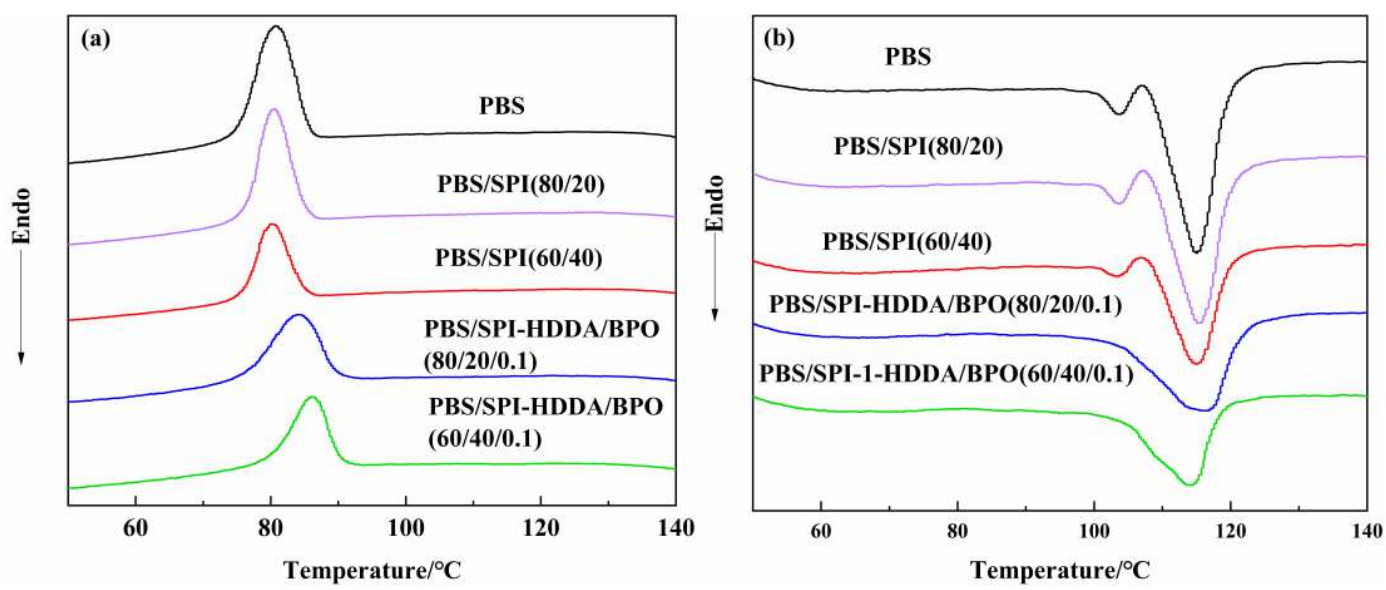

Fig. 8 DSC curves of PBS and PBS composites.

(a) the cooling curves, (b) the second heating curves. 
Table 6 DSC data of PBS and PBS composites

\begin{tabular}{cccccc}
\hline Sample & \multicolumn{3}{c}{ Cooling } & \multicolumn{3}{c}{ Second heating } \\
& $\mathrm{T}_{\mathrm{c}}{ }^{\text {on }}\left({ }^{\circ} \mathrm{C}\right)$ & $\mathrm{T}_{\mathrm{c}}{ }^{\mathrm{P}}\left({ }^{\circ} \mathrm{C}\right)$ & $\mathrm{T}_{\mathrm{c}}{ }^{\text {on }}-\mathrm{T}_{\mathrm{c}}{ }^{\mathrm{P}}\left({ }^{\circ} \mathrm{C}\right)$ & $\mathrm{T}_{\mathrm{m}}\left({ }^{\circ} \mathrm{C}\right)$ & $\mathrm{X}_{\mathrm{c}}(\%)$ \\
PBS & 86.50 & 80.96 & 5.54 & $103.49 / 115.31$ & 27.56 \\
PBS/SPI (80/20) & 86.14 & 80.51 & 5.63 & $103.49 / 115.32$ & 31.98 \\
PBS/SPI (60/40) & 85.99 & 80.08 & 5.91 & $103.37 / 115.15$ & 30.90 \\
PBS/SPI-HDDA/BPO & & & & & \\
$(80 / 20 / 0.1)$ & 91.59 & 84.10 & 7.49 & 116.57 & 34.43 \\
PBS/SPI-HDDA/BPO & & & & & \\
$(60 / 40 / 0.1)$ & 92.46 & 86.10 & 6.36 & 114.06 & 36.96 \\
\hline
\end{tabular}

The DSC curves of PBS and PBS composites are shown in Fig. 8 and DSC data are listed in Table 6. Figure 8(a) presents the cooling curves of the samples, the onset $\left(\mathrm{T}_{\mathrm{c}}{ }^{\text {on }}\right)$ and peak $\left(\mathrm{T}_{\mathrm{c}}{ }^{\mathrm{P}}\right)$ crystallization temperatures and their difference $\left(\mathrm{T}_{\mathrm{c}}{ }^{\text {on }}-\mathrm{T}_{\mathrm{c}}{ }^{\mathrm{P}}\right)$ of the pure PBS are $86.50,80.96$ and $5.54{ }^{\circ} \mathrm{C}$, respectively. Compared with the pure PBS, the $\mathrm{T}_{\mathrm{c}}{ }^{\mathrm{P}}$ and $\left(\mathrm{T}_{\mathrm{c}}{ }^{\text {on }}-\mathrm{T}_{\mathrm{c}}{ }^{\mathrm{P}}\right)$ of PBS/SPI composites are basically unchanged, indicating that the crystallization behavior of PBS is not influenced by SPI. However, the $\mathrm{T}_{\mathrm{c}}{ }^{\mathrm{P}}$ values of PBS/SPI-HDDA/BPO composites shift to higher temperatures, indicating that the crosslinked graft copolymer provides nucleation ability for PBS. [21] However, the $\left(\mathrm{T}_{\mathrm{c}}{ }^{\text {on }}-\mathrm{T}_{\mathrm{c}}{ }^{\mathrm{P}}\right)$ values of PBS/SPI-HDDA/BPO composites are larger than those of the pure PBS and PBS/SPI composites, suggesting that the presence of SPI-g-HDDA-g-PBS enhances the interfacial adhesion and improves the compatibility between PBS and SPI, and the crystallization of PBS is disturbed by the 
grafts, resulting in prolonged crystallization process.

The second heating curves of the specimens are presented in Fig. 8(b). Double melting peaks exist on curves of the pure PBS and PBS/SPI composites, attributing to the melting-recrystallization mechanism. During the cooling process, two stacks of lamellae with different sizes are formed, namely metastable and perfect lamellae. During the heating program, the imperfect lamellae melt firstly, and then, they rearrange into perfect lamellae. Therefore, the low and high temperature melting peaks are attributed to the melting of metastable and perfect lamellae, respectively. [51] However, there are single melting peaks on the curves of PBS/SPI-HDDA/BPO composites. Because the crosslinked graft copolymer in PBS/SPI-HDDA/BPO composites enhances the interfacial adhesion between PBS and SPI, resulting in single population of lamellae with a wide size distribution. Therefore, the broad crystallization and melting peaks are observed during cooling and melting processes for PBS/SPI-HDDA/BPO composites.

Table 6 lists the crystallinities of PBS and PBS composites. Compared with PBS/SPI composites, the crystallinities of PBS/SPI-HDDA/BPO composites increase obviously, indicating that the crosslinked graft copolymer serves as the nucleating agent to facilitate the crystallization of PBS.

\section{WAXD characterizations}




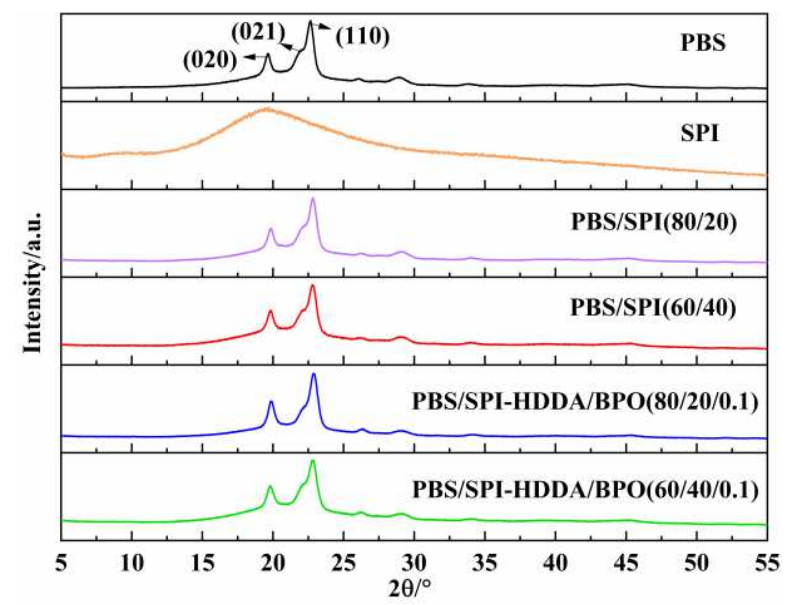

Fig. 9 WAXD curves of SPI, PBS and PBS composites.

Table 7 WAXD data for SPI, PBS and PBS composites

\begin{tabular}{|c|c|c|c|}
\hline Sample & Crystal plane & $2 \theta\left(^{\circ}\right)$ & Crystallite size $(\mathrm{nm})$ \\
\hline PBS & & 19.60 & 17.96 \\
\hline PBS/SPI (80/20) & & 19.86 & 17.35 \\
\hline PBS/SPI (60/40) & 020 & 19.84 & 17.81 \\
\hline PBS/SPI-HDDA/BPO (80/20/0.1) & & 19.84 & 16.35 \\
\hline PBS/SPI-HDDA/BPO (60/40/0.1) & & 19.78 & 16.45 \\
\hline PBS & & 22.66 & 10.70 \\
\hline PBS/SPI (80/20) & & 22.83 & 10.39 \\
\hline PBS/SPI (60/40) & 110 & 22.78 & 9.62 \\
\hline PBS/SPI-HDDA/BPO (80/20/0.1) & & 22.86 & 10.66 \\
\hline PBS/SPI-HDDA/BPO (60/40/0.1) & & 22.76 & 9.74 \\
\hline
\end{tabular}

The crystal structures of SPI, PBS and PBS composites are studied using WAXD analyses (Fig. 9). For the pure PBS, there are two strong diffraction peaks locate at $19.6^{\circ}$ and $22.66^{\circ}$, and an inconspicuous peak locates at $21.8^{\circ}$, corresponding to (020), (110) and (021) crystal planes, respectively. [52] Two broad diffraction peaks of 
amorphous SPI locate at $2 \theta=9.4^{\circ}$ and $19.8^{\circ}$, corresponding to the SPI secondary conformation $\alpha$-helix and $\beta$-sheet, respectively. [53] In the blends of PBS and SPI, the characteristic peaks of SPI disappear and those of PBS change little, indicating that the crystal form of PBS is not changed by the addition of SPI, BPO and HDDA.

Table 7 shows the grain sizes of PBS and PBS composites. The grain sizes of (020) and (110) planes of PBS/SPI and PBS/SPI-HDDA/BPO composites are smaller than those of the pure PBS, especially for the grain sizes of (020) plane of PBS/SPI-HDDA/BPO composites, indicating that the grain refinement may be related to the nucleation effect of the crosslinked graft copolymer in PBS/SPI-HDDA/BPO composites.

\section{Mechanical tests}
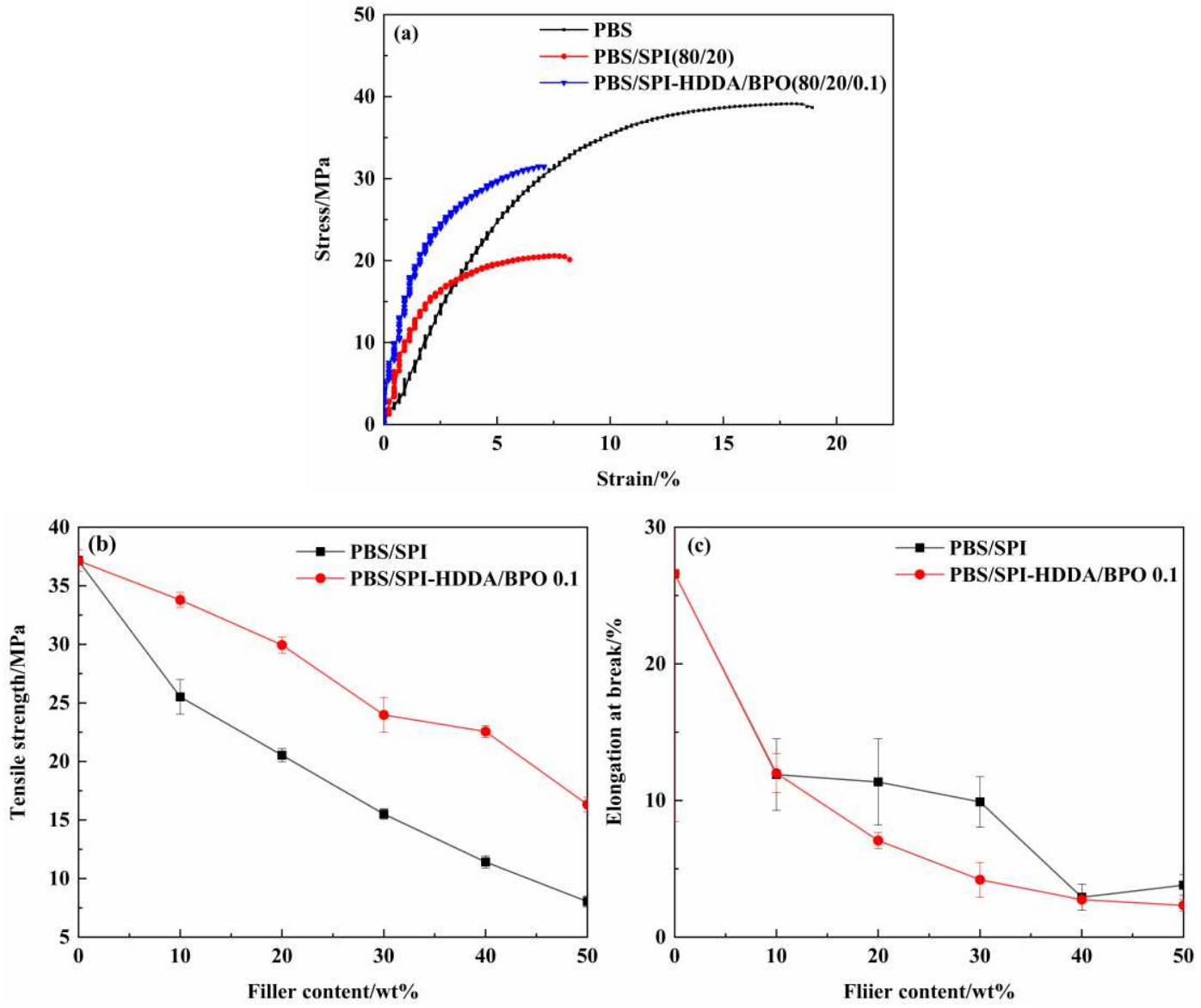
Fig. 10 Mechanical properties of PBS and PBS composites.

(a) Stress-strain curves, (b) Tensile strength, (c) Elongation at break.

Figure 10 shows the mechanical properties of the PBS, PBS/SPI and PBS/SPI-HDDA/BPO 0.1 composites. The tensile stress-strain curves of the PBS, PBS/SPI (80/20) and PBS/SPI-HDDA/BPO (80/20/0.1) composites are presented in Fig. 10(a). All samples exhibit continuous deformation until final fracture. The Young's moduli of PBS, PBS/SPI (80/20) and PBS/SPI-HDDA/BPO (80/20/0.1) composite are 500, 840 and $1305 \mathrm{MPa}$, respectively, showing the increase in the stiffness of the composites, especially for PBS/SPI-HDDA/BPO (80/20/0.1) composite. The rigid SPI fillers disperse in the PBS matrix, which restrict the molecular mobility of PBS. The restriction is reflected as an increase in the modulus of the blends. [54] Moreover, the crosslinked graft copolymer in the PBS/SPI-HDDA/BPO composite enhances the interaction between two phases, leading to the further improvement of the stiffness.

Figures 10(b) and 10(c) present the tensile strength and elongation at break of PBS and PBS composites. The tensile strength and elongation at break of PBS composites are lower than those of the pure PBS, indicating that the immiscible SPI phase destroys the original continuous PBS matrix, resulting in poor interfacial adhesion between two phases. The SEM micrographs (Fig. 1) show that the fractured surfaces are coarse, accompanying with large holes and interstices for PBS/SPI composites. Zhou et al. [55] also found the reduction in mechanical properties of PBAT/SM blends due to the poor interfacial adhesion. 
Moreover, the tensile strength curve of PBS/SPI-HDDA/BPO composites is higher than that of PBS/SPI composites, indicating that the crosslinked graft copolymer enhances the adhesion between PBS and SPI. As shown in Fig. 1, fewer holes and interstices are observed on the fractured surfaces of PBS/SPI-HDDA/BPO composites. Compared with PBS/SPI composites, the elongation at break of PBS/SPI-HDDA/BPO composites decreases a little. Because some crosslinked networks present in PBS/SPI-HDDA/BPO composites, which restricts the movement of polymer chains and matrix deformation, contributing to the lower elongation at break of PBS/SPI-HDDA/BPO composites.

\section{Water absorption measurements}

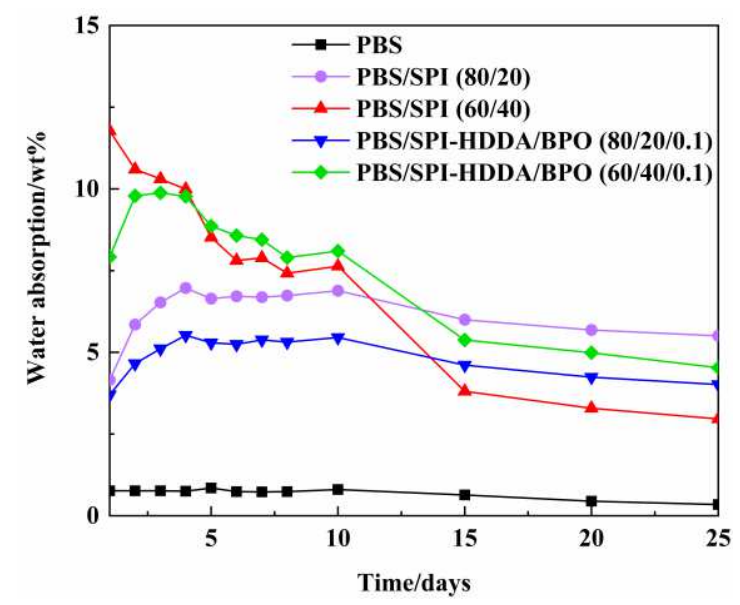

Fig. 11 Water absorption curves of PBS and PBS composites.

Figure 11 shows the water absorption curves of the pure PBS, PBS/SPI and PBS/SPI-HDDA/BPO composites within 25 days. The water absorption of the pure PBS remains constant over time because of the hydrophobicity of PBS. [56] For PBS/SPI (80/20) composite, the addition of SPI results in an obvious increase in the water absorption within the first five days, indicating that SPI absorbs water due to its hydrophilic nature. [57] Moreover, the water absorption of PBS/SPI-HDDA/BPO 
(80/20/0.1) composite is lower than that of PBS/SPI (80/20) composite, indicating that the crosslinked graft copolymer enhances the adhesion between PBS and SPI, and thus improves the water resistance of the composites. Xu et al. [58] found that the water resistance of SPI films was increased due to the formation of crosslinked network structure between 1,2,3-propanetriol diglycidyl ether (PTGE) and SPI. Das et al. [16] also found that the water absorption of crosslinked SPC decreased due to the increase of the percentage of formaldehyde or furfural.

For PBS/SPI (60/40) composite, the water absorption decreases significantly with time, showing that SPI dissolves in water. As shown in SEM micrographs (Fig. 1), many holes and cracks are observed on the fractured surface of PBS/SPI composites, and thus SPI particles may detach easily from the matrix at $40 \%$ content. The crosslinked graft copolymer forms a network structure to enhance the adhesion between PBS and SPI phases, showing that the water absorption of PBS/SPI (60/40) composite is lower than that of PBS/SPI-HDDA/BPO (60/40/0.1) composite.

\section{Conclusions}

The reactive blending method is used to produce PBS/SPI bio-composites due to its low-cost and facile production. SEM, FTIR, DMA and Soxhlet extraction experiments indicate the existence of the branched graft copolymer (SPI-g-HDDA-g-PBS) in the PBS/SPI-HDDA/BPO composites, which improves the compatibility and adhesion between the PBS matrix and SPI phase. The rheological analyses indicate that SPI-g-HDDA-g-PBS enhances the entanglement between two phases and increases the melt viscosity and elasiticity. The contact angle results show that the 
hydrophobicity of PBS/SPI-HDDA/BPO composites is higher than that of PBS/SPI composites because the existence of SPI-g-HDDA-g-PBS facilitates to form PBS-rich surfaces. It is found that the thermal stability of the composites is lower than the pure PBS due to the poor thermal stability of SPI. In addition, the presence of SPI-g-HDDA-g-PBS results in improved thermal stability. The DSC results show that the crosslinked graft copolymer serves as the nucleating agent to promote the crystallization of PBS in the composites. The WAXD results show that the addition of SPI, BPO and HDDA does not modify the crystal form of PBS. The tensile strength of PBS/SPI-HDDA/BPO composites is higher than that of PBS/SPI composites whereas the elongation at break of the former is lower than the latter due to the crosslinked graft copolymer enhances the adhesion between PBS and SPI. In addition, the enhanced adhesion between PBS and SPI by the grafts also improves the water resistance of the composites.

\section{Acknowledgements}

This work was supported by the Priority Academic Program Development of Jiangsu Higher Education Institutions (PAPD).

\section{Declarations}

Conflict of interest The authors have no conflicts of interest to declare that are relevant to the content of this article.

Data Availability The datasets generated during and/or analysed during the current study are 
available from the corresponding author on reasonable request.

Authors' Contributions Q. Dou contributed to the study conception and design. Material preparation, characterization and analysis were performed by X. Zhou. The first draft of the manuscript was written by X. Zhou and Q. Dou commented on previous versions of the manuscript. All authors read and approved the final manuscript.

\section{References}

1. de Matos Costa, A.R., Crocitti, A., Hecker De Carvalho, L., Carroccio, S.C., Cerruti, P., Santagata, G., 2020, Properties of Biodegradable Films Based on Poly(butylene Succinate) (PBS) and Poly(butylene Adipate-co-Terephthalate) (PBAT) Blends. Polymers. 12, 2317. https://doi.org/10.3390/polym12102317

2. Rai, P., Mehrotra, S., Priya, S., Gnansounou, E., Sharma, S.K., 2021, Recent advances in the sustainable design and applications of biodegradable polymers. Bioresource Technology.325, 124739. https://doi.org/10.1016/j.biortech.2021.124739

3. Jost, V., 2018, Packaging related properties of commercially available biopolymers - An overview of the status quo. Express Polymer Letters. 12, 429-435. https://doi.org/10.3144/expresspolymlett.2018.36

4. Messin, T., Marais, S., Follain, N., Guinault, A., Gaucher, V., Delpouve, N., Sollogoub, C., 2020, Biodegradable PLA/PBS multinanolayer membrane with enhanced barrier performances. Journal of Membrane Science. 598, 117777. https://doi.org/10.1016/j.memsci.2019.117777

5. Boonprasertpoh, A., Pentrakoon, D., Junkasem, J., 2020, Effect of PBAT on 
physical, morphological, and mechanical properties of PBS/PBAT foam. Cellular Polymers. 39, 31-41. https://doi.org/10.1177/0262489319873859

6. Ahmad Saffian, H., Abdan, K., Ali Hassan, M., Ibrahim, A., 2017, Characterization, morphology, and biodegradation of bioplastic fertilizer $(\mathrm{BpF})$ composites made of poly(butylene succinate) blended with oil palm biomass and fertilizer. Polymer Composites. 38, 2577-2583. https://doi.org/10.1002/pc.23849

7. Henke, L., Zarrinbakhsh, N., Endres, H., Misra, M., Mohanty, A.K., 2017, Biodegradable and Bio-based Green Blends from Carbon Dioxide-Derived Bioplastic and Poly(Butylene Succinate). Journal of Polymers and the Environment. 25, 499-509. https://doi.org/10.1007/s10924-016-0828-X

8. Xu, J., Chen, Y., Tian, Y., Yang, Z., Zhao, Z., Du, W., Zhang, X., 2021, Effect of ionic liquid 1-buyl-3-methylimidazolium halide on the structure and tensile property of PBS/corn starch blends. International Journal of Biological Macromolecules. 172, 170-177. https://doi.org/10.1016/j.ijbiomac.2021.01.062

9. Koshy, R.R., Mary, S.K., Thomas, S., Pothan, L.A., 2015, Environment friendly green composites based on soy protein isolate - A review. Food Hydrocolloid 50, 174-192. https://doi.org/10.1016/j.foodhyd.2015.04.023

10. Xing, B., Xu, X., Hu, W., Ni, R., Zhao, Y., 2021, Highly Thermal - Resistant and Biodegradable Textile Sizes from Glycols Modified Soy Proteins for Remediation of Textile Effluents. Macromolecular Materials and Engineering. 306, 2000751. https://doi.org/10.1002/mame.202000751

11. Zhu, R., Liu, H., Zhang, J., 2011, Compatibilizing Effects of Maleated Poly(lactic 
acid) (PLA) on Properties of PLA/Soy Protein Composites. Industrial and Engineering Chemistry Research. 51, 7786-7792. https://doi.org/10.1021/ie300118x

12. Feng, J., Berton-Carabin, C.C., Ataç Mogol, B., Schroën, K., Fogliano, V., 2021, Glycation of soy proteins leads to a range of fractions with various supramolecular assemblies and surface activities. Food Chemistry. 343, 128556. https://doi.org/10.1016/j.foodchem.2020.128556

13. Wang, Y., Wang, Q., Zhu, Y., Shen, Y., Cheng, S., Zheng, H., Xu, Y., 2021, Structure and properties of oxycellulose fabric crosslinked with soy protein. Carbohydrate Polymers. 257, 117548. https://doi.org/10.1016/j.carbpol.2020.117548

14. Cuadri, A.A., Romero, A., Bengoechea, C., Guerrero, A., 2017, Natural superabsorbent plastic materials based on a functionalized soy protein. Polymer Testing. 58, 126-134. https://doi.org/10.1016/j.polymertesting.2016.12.024

15. Hao, X., Fan, D., 2018, Preparation and characterization of epoxy-crosslinked soy protein adhesive. Journal of Adhesion Science and Technology. 32, 2682-2692. https://doi.org/10.1080/01694243.2018.1517488

16. Das, S.N., Routray, M., Nayak, P.L., 2008, Spectral, Thermal, and Mechanical Properties of Furfural and Formaldehyde Cross-Linked Soy Protein Concentrate: A Comparative Study. Polymer-Plastics Technology and Engineering. 47, 576-582. https://doi.org/10.1080/03602550701866634

17. Mekonnen, T., Misra, M., Mohanty, A.K., 2015, Fermented Soymeals and Their Reactive Blends with Poly(butylene adipate-co-terephthalate) in Engineering Biodegradable Cast Films for Sustainable Packaging. ACS Sustainable Chemistry and 
Engineering. 4, 782-793. https://doi.org/10.1021/acssuschemeng.5b00782

18. Thakur, M.K., Thakur, V.K., Gupta, R.K., Pappu, A., 2015, Synthesis and Applications of Biodegradable Soy Based Graft Copolymers: A Review. ACS

$\begin{array}{llll}\text { Sustainable } \quad \text { Chemistry } & \text { and }\end{array}$ https://doi.org/10.1021/acssuschemeng.5b01327

19. Rahman, M.M., Byanju, B., Grewell, D., Lamsal, B.P., 2020, High-power sonication of soy proteins: Hydroxyl radicals and their effects on protein structure.

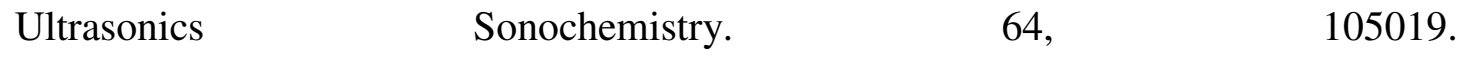
https://doi.org/10.1016/j.ultsonch.2020.105019

20. Chen, F., Zhang, J., 2010, In-situ poly(butylene adipate-co-terephthalate)/soy protein concentrate composites: Effects of compatibilization and composition on properties. Polymer 51, 1812-1819. https://doi.org/10.1016/j.polymer.2010.02.035

21. Li, Y., Zeng, J., Li, W., Yang, K., Wang, X., Wang, Y., 2009, Rheology, Crystallization, and Biodegradability of Blends Based on Soy Protein and Chemically Modified Poly(butylene succinate). Industrial and Engineering Chemistry Research. 48, 4817-4825. https://doi.org/10.1021/ie801718f

22. Ku-Marsilla, K.I., Verbeek, C.J.R., 2014, Mechanical Properties of Thermoplastic Protein From Bloodmeal and Polyester Blends. Macromolecular Materials and Engineering. 299, 885-895. https://doi.org/10.1002/mame.201300396

23. Bonham, S., Misra, M., Mohanty, A.K., 2011, Effect of Co-Rotation and Counter-Rotation Extrusion Processing on the Thermal and Mechanical Properties, and Morphology of Plasticized Soy Protein Isolate and Poly(butylene succinate) 
Blends. Macromolecular Materials and Engineering. 296, 788-801. https://doi.org/10.1002/mame.201000404

24. Reddy, M.M., Mohanty, A.K., Misra, M., 2012, Biodegradable Blends From Plasticized Soy Meal, Polycaprolactone, and Poly(butylene succinate). Macromolecular Materials and Engineering. 297, 455-463. https://doi.org/10.1002/mame.201100203

25. Renoux, J., Dani, J., Douchain, C., Prashantha, K., Krawczak, P., 2018, Simultaneous plasticization and blending of isolate soy protein with poly[(butylene succinate)-co-adipate] by one-step extrusion process. Journal of Applied Polymer Science.135, 46442. https://doi.org/10.1002/app.46442

26. Chen, F., Zhang, J., 2009, A new approach for morphology control of poly(butylene adipate-co-terephthalate) and soy protein blends. Polymer. 50, 3770-3777. https://doi.org/10.1016/j.polymer.2009.06.004

27. Anstey, A., Muniyasamy, S., Reddy, M.M., Misra, M., Mohanty, A., 2014, Processability and Biodegradability Evaluation of Composites from Poly(butylene succinate) (PBS) Bioplastic and Biofuel Co-products from Ontario. Journal of $\begin{array}{llll}\text { Polymers } \text { and } & \text { 209-218. }\end{array}$ https://doi.org/10.1007/s10924-013-0633-8

28. Coltelli, M., Aliotta, L., Gigante, V., Bellusci, M., Cinelli, P., Bugnicourt, E., Schmid, M., Staebler, A., Lazzeri, A., 2020, Preparation and Compatibilization of PBS/Whey Protein Isolate Based Blends. Molecules. 25, 3313. https://doi.org/10.3390/molecules25143313 
29. Feng, B., Wang, D., Li, Y., Qian, J., Yu, C., Wang, M., Luo, D., Wei, S., 2020, Mechanical Properties of a Soy Protein Isolate-Grafted-Acrylate (SGA) Copolymer $\begin{array}{llllll}\text { Used for } & \text { Wood } & \text { Coatings. } & \text { Polymers. } & 12, & \end{array}$ https://doi.org/10.3390/polym12051137

30. Mungara, P., Chang, T., Zhu, J., Jane, J., 2002, Processing and Physical Properties of Plastics Made from Soy Protein Polyester Blends. Journal of Polymers and the Environment. 10, 31-37. https://doi.org/10.1023/A:1021018022824

31. Saxena, D., Maiti, P., 2021, Utilization of ABS from plastic waste through single-step reactive extrusion of LDPE/ABS blends of improved properties. Polymer. 221, 123626. https://doi.org/10.1016/j.polymer.2021.123626

32. Yan, Y., Dou, Q., 2021, Effect of Peroxide on Compatibility, Microstructure, Rheology, Crystallization, and Mechanical Properties of PBS/Waxy Starch Composites. Starch-Stärke 73, 2000184. https://doi.org/10.1002/star.202000184

33. Bai, J., Pei, H., Zhou, X., Xie, X., 2021, Reactive compatibilization and properties of low-cost and high-performance PBAT/thermoplastic starch blends. European Polymer Journal. 143, 110198. https://doi.org/10.1016/j.eurpolymj.2020.110198

34. Graiver, D., Waikul, L.H., Berger, C., Narayan, R., 2004, Biodegradable soy protein-polyester blends by reactive extrusion process. Journal of Applied Polymer Science. 92, 3231-3239. https://doi.org/10.1002/app.20344

35. Chen, L., Cheng, H., Xiong, J., Zhu, Y., Zhang, H., Xiong, X., Liu, Y., Yu, J., Guo, Z., 2018, Improved Mechanical Properties of Poly(butylene succinate) Membrane by Co-electrospinning with Gelatin. Chinese Journal of Polymer Science. 
36, 1063-1069. https://doi.org/10.1007/s10118-018-2112-0

36. Luo, X., Li, J., Lin, X., 2012, Effect of gelatinization and additives on morphology and thermal behavior of corn starch/PVA blend films. Carbohydrate Polymers. 90, 1595-1600. https://doi.org/10.1016/j.carbpol.2012.07.036

37. Ahmad Thirmizir, M.Z., Mohd Ishak, Z.A., Mat Taib, R., C. Kanapathi Pillai, K.S.K., Salim, M.S., Hassan, A., Abu Bakar, M.B., 2021, The effects of melt grafted maleated polybutylene succinate on the properties of poly(hydroxybutyrate-co-hydroxyhexanoate)/polybutylene succinate blends. Journal of Vinyl and Additive Technology.1-22. https://doi.org/10.1002/vnl.21828

38. Chen, X., Ru, Y., Chen, F., Wang, X., Zhao, X., Ao, Q., 2013, FTIR spectroscopic characterization of soy proteins obtained through AOT reverse micelles. Food Hydrocolloids. 31, 435-437. https://doi.org/10.1016/j.foodhyd.2012.11.017

39. Lin, N., Yu, J., Chang, P.R., Li, J., Huang, J., 2011, Poly(butylene succinate)-based biocomposites filled with polysaccharide nanocrystals: Structure and properties. Polymer Composites. 32, 472-482. https://doi.org/10.1002/pc.21066

40. Petersson, L., Oksman, K., 2006, Biopolymer based nanocomposites: Comparing layered silicates and microcrystalline cellulose as nanoreinforcement. Composites $\begin{array}{llll}\text { Science } \quad \text { and } & \text { Technology. }\end{array}$ https://doi.org/10.1016/j.compscitech.2005.12.010

41. Chikh, A., Benhamida, A., Kaci, M., Bourmaud, A., Bruzaud, S., 2017, Recyclability assessment

of poly(3-hydroxybutyrate-co-3-hydroxyvalerate)/poly(butylene succinate) blends: 
Combined influence of sepiolite and compatibilizer. Polymer Degradation and Stability. 142, 234-243. https://doi.org/10.1016/j.polymdegradstab.2017.07.014

42. Chen, X., Gug, J., Sobkowicz, M.J., 2014, Role of polymer/filler interactions in the linear viscoelasticity of poly(butylene succinate)/fumed silica nanocomposite. $\begin{array}{lllll}\text { Composites } & \text { Science } & \text { and }\end{array}$ https://doi.org/10.1016/j.compscitech.2014.01.025

43. Chen, F., Zhang, J., 2010, Effects of Plasticization and Shear Stress on Phase Structure Development and Properties of Soy Protein Blends. ACS Applied Materials and Interfaces. 2, 3324-3332. https://doi.org/10.1021/am100751c

44. Cassagnau, P., 2008, Melt rheology of organoclay and fumed silica nanocomposites. $\quad$ Polymer. $\quad 49, \quad 2183-2196$. https://doi.org/10.1016/j.polymer.2007.12.035

45. Oliviero, M., Sorrentino, L., Cafiero, L., Galzerano, B., Sorrentino, A., Iannace, S., 2015, Foaming behavior of bio-based blends based on thermoplastic gelatin and poly(butylene succinate). Journal of Applied Polymer Science. 132, 42704. https://doi.org/10.1002/app.42704

46. Su, F., Wang, J., Zhu, S., Liu, S., Yu, X., Li, S., 2015, Synthesis and characterization of novel carboxymethyl chitosan grafted polylactide hydrogels for controlled drug delivery. Polymers for Advanced Technologies. 26, 924-931. https://doi.org/10.1002/pat.3503

47. Fang, Q., Zhu, M., Yu, S., Sui, G., Yang, X., 2016, Studies on soy protein isolate/polyvinyl alcohol hybrid nanofiber membranes as multi-functional 
eco-friendly filtration materials. Materials Science and Engineering: B 214, 1-10. https://doi.org/10.1016/j.mseb.2016.08.004

48. Horowitz, H.H., Metzger, G., 1963, A New Analysis of Thermogravimetric Traces. Analytical Chemistry. 35, 1464-1468. https://doi.org/10.1021/ac60203a013

49. Dash, S., Swain, S.K., 2013, Effect of nanoboron nitride on the physical and chemical properties of soy protein. Composites Science and Technology. 84, 39-43. https://doi.org/10.1016/j.compscitech.2013.05.004

50. Mahmoud, W.E., Al-Heniti, S.H., 2011, Evaluation and modeling of thermal kinetic degradation for PVA doped PbS quantum dot. Materials Research Bulletin. 46, 1366-1371. https://doi.org/10.1016/j.materresbull.2011.05.017

51. Qiu, Z., Komura, M., Ikehara, T., Nishi, T., 2003, DSC and TMDSC study of melting behaviour of poly(butylene succinate) and poly(ethylene succinate). Polymer. 44, 7781-7785. https://doi.org/10.1016/j.polymer.2003.10.045

52. Xu, Y., Xu, J., Guo, B., Xie, X., 2007, Crystallization kinetics and morphology of biodegradable poly(butylene succinate-co-propylene succinate)s. Journal of Polymer Science. Part B, Polymer Physics. 45, 420-428. https://doi.org/10.1002/polb.20877

53. Han, Y., Li, K., Chen, H., Li, J., 2017, Properties of Soy Protein Isolate Biopolymer Film Modified by Graphene. Polymers (Basel). 9, 312. https://doi.org/10.3390/polym9080312

54. Bautista, M., Martínez De Ilarduya, A., Alla, A., Vives, M., Morató, J., Muñoz-Guerra, S., 2016, Cationic poly(butylene succinate) copolyesters. European Polymer Journal. 75, 329-342. https://doi.org/10.1016/j.eurpolymj.2015.12.012 
55. Zhou, X., Mohanty, A., Misra, M., 2013, A New Biodegradable Injection Moulded Bioplastic from Modified Soy Meal and Poly(butylene adipate-co-terephthalate): Effect of Plasticizer and Denaturant. Journal of Polymers and the Environment. 21, 615-622. https://doi.org/10.1007/s10924-013-0578-y

56. Ku-Marsilla, K.I., Verbeek, C.J.R., 2015, Compatibilization of Protein Thermoplastics and Polybutylene Succinate Blends. Macromolecular Materials and Engineering. 300, 161-171. https://doi.org/10.1002/mame.201400141

57. Wang, Y., Zhang, A., Wang, Y., Wang, X., Xu, N., Jiang, L., 2020, Effects of irradiation on the structure and properties of glycosylated soybean proteins. Food and Function. 11, 1635-1646. https://doi.org/10.1039/C9FO01879D

58. Xu, F., Zhang, W., Zhang, S., Li, L., Li, J., Zhang, Y., 2015, Preparation and characterization of poly(vinyl alcohol) and 1,2,3-propanetriol diglycidyl ether incorporated soy protein isolate-based films. Journal of Applied Polymer Science. 132., 42578. https://doi.org/10.1002/app.42578 